
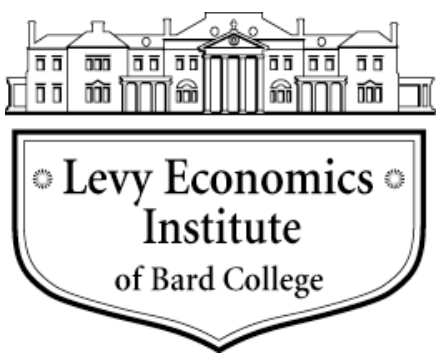

Working Paper No. 781

\title{
A Stock-flow Approach to a General Theory of Pricing
}

by

Philip Pilkington
Kingston University

December 2013

The Levy Economics Institute Working Paper Collection presents research in progress by Levy Institute scholars and conference participants. The purpose of the series is to disseminate ideas to and elicit comments from academics and professionals.

Levy Economics Institute of Bard College, founded in 1986, is a nonprofit, nonpartisan, independently funded research organization devoted to public service. Through scholarship and economic research it generates viable, effective public policy responses to important economic problems that profoundly affect the quality of life in the United States and abroad.

Levy Economics Institute P.O. Box 5000

Annandale-on-Hudson, NY 12504-5000

http://www.levyinstitute.org

Copyright (C) Levy Economics Institute 2013 All rights reserved 


\begin{abstract}
The paper seeks to lay out a stock-flow-based theoretical framework that provides a foundation for a general theory of pricing. Contemporary marginalist economics is usually based on the assumption that prices are set in line with the value placed on goods by consumers. It does not take into account expectations, or the fact that real goods are often simultaneously assets. Meanwhile, contemporary theories of asset markets are flawed in that they either rely, implicitly or explicitly, on a market equilibrium framework or provide no framework at all. This paper offers a working alternative that relies, not on a market equilibrium framework, but rather on a stock-flow equilibrium framework. In doing so, we lay out a properly general theory of pricing that can be applied to any market - whether financial, real, or a real market that has been financialized - and which does not require that prices inevitably tend toward some prespecified market equilibrium.
\end{abstract}

Keywords: Pricing; Prices; Asset Pricing; Assets; Financial Assets; Financial Pricing; Disequilibrium Pricing; Equilibrium; Disequilibrium; Market Structure; Teleology

JEL Classifications: B4, D4, D5, D8, E3, E4, G1 


\section{List of Mathematical Terms}

In order of appearance:

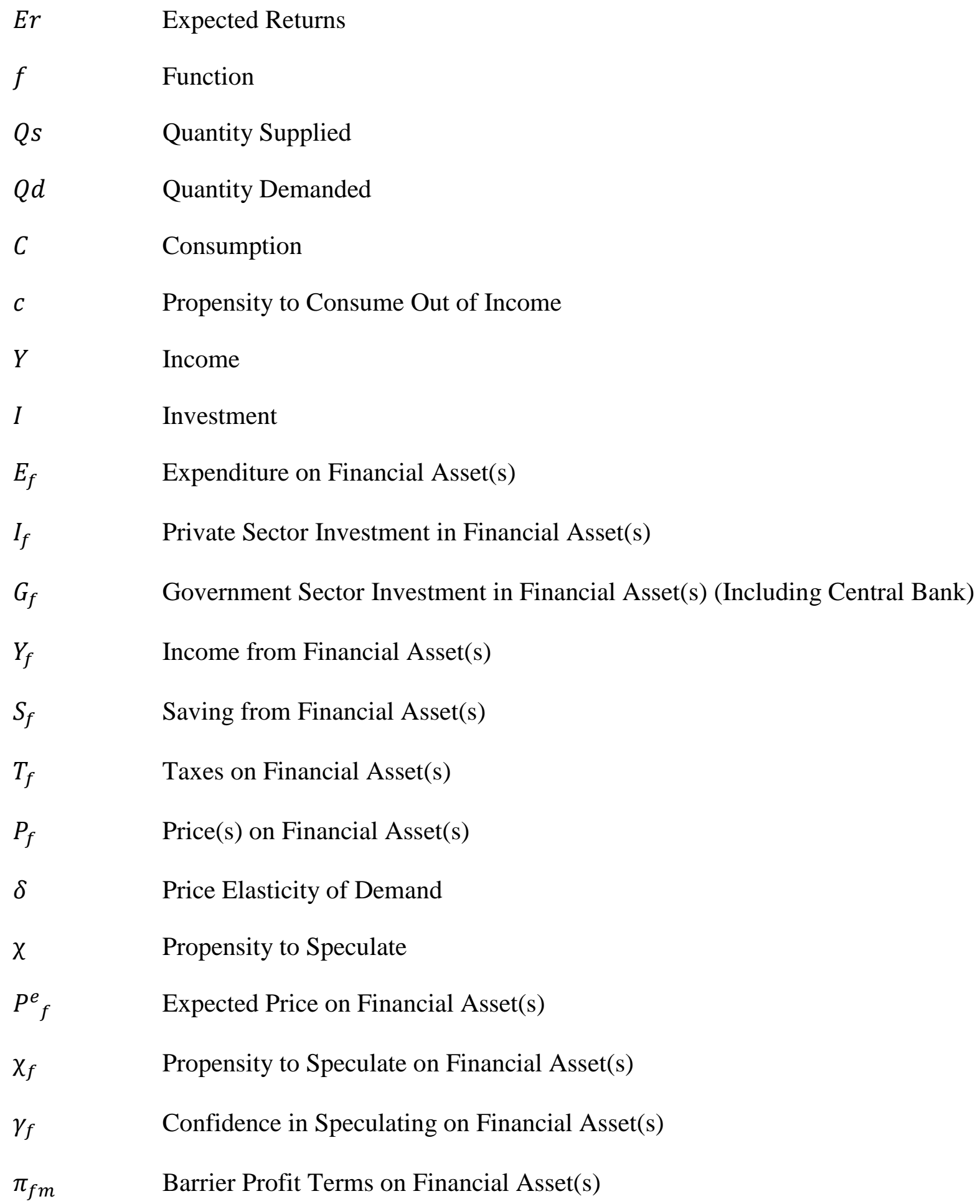




$\begin{array}{ll}q & \text { Propensity to Increase Production/Offload Inventory } \\ Z & \text { Capacity to Increase Production/Offload Inventory } \\ e & \text { Expectations } \\ i & \text { Interest Rate } \\ I_{r} & \text { Private Investment in Real Asset(s) } \\ G_{r} & \text { Government Investment in Real Asset(s) } \\ C_{r} & \text { Consumption of Real Asset(s) } \\ Y_{r} & \text { Real Income } \\ T_{r} & \text { Taxes on Real Transactions } \\ P_{r} & \text { Price on Real Asset(s) } \\ P_{r}^{e} & \text { Expected Price on Real Asset(s) } \\ \gamma_{r} & \text { Confidence in Speculating on Real Assets } \\ \pi_{r m} & \text { Price Barrier Term on Real Asset(s) }\end{array}$




\section{INTRODUCTION}

Since the financial crisis of 2008 economists have recognised that markets generally are becoming increasingly financialised and that markets with a financial component are subject to bubbles which can bring the entire economy to its knees (Wray 2008). Meanwhile, many theories of financial markets have been called into question due to the crisis. Thus, at the very time that economists need theories of financial markets that they can use to understand the thrust of financialisation in the economy the most, they find that these theories are open to doubt.

In this paper we will survey some of the theories of asset pricing that already exist in the literature. In doing so we will try to highlight their shortcomings and bring out certain common properties that impede their functionality. The implicit question being asked will be: why, even though these theories purport to deal with speculation in financial markets, have they proved inadequate at capturing the real-life manner in which financial and financialised markets operate? We will explore in depth the concept of 'market equilibrium' and make the case that this is the main impediment to existing theories realistically providing a framework with which we can understand contemporary financial markets. We will look to another type of theoretical framework, the Keynesian stock-flow equilibrium framework, in order to understand how conceptions of market equilibrium can be circumvented.

We will then go on to lay out such a framework. In doing so we will seek to keep the best aspects of existing theories intact, while at the same time ensuring that we remove any notion of market equilibrium and replace it with a new structure based upon a notion of stockflow equilibrium. We must also ensure that this framework can accommodate not just speculation as an inherent feature of markets, but can also accommodate markets that are not generally thought to have similar characteristics to pure asset markets. In doing this we can ensure that the framework is up to the task of dealing with the increasing number of financialised markets that we see in the real-world.

\section{EXISTING LITERATURE}

In order to deal with the existing literature, we must divide it into two categories: theoretical and empirical. While the various strands of the theoretical literature are somewhat limited, the scope of the empirical literature is enormous. For this reason, we have decided to focus on a single 
topic; namely, the run-up in oil prices from roughly 2003 to the time of this writing. In doing this we will not so much be interested in whether or not the oil market is subject to speculation in these years but rather the theoretical framework that is being used to account for the price rises, especially in the literature that considers these price rises to be in part due to speculation.

\subsection{Theoretical Literature}

The best approach to the theoretical literature is to examine what much of it is founded upon. The theory underlying most mainstream conceptions of financial markets since the 1970s is the Efficient Markets Hypothesis (EMH) as developed by Eugene Fama in his 1970 paper "Efficient Capital Markets: A Review of Theory and Empirical Work" (Fama 1970). The idea lying behind the paper, however, goes back to Paul Samuelson who summarises it neatly as such:

In competitive markets there is a buyer for every seller. If one could be sure that a price will rise, it would already have risen."... [Competitive] prices must display price changes over time, $X_{t+1}-X_{t}$, that perform a random walk with no predictable bias. (Samuelson 1965, p41)

The idea here is that markets for financial assets will always price in the relevant underlying values or alternatively, that the price of an asset is equal to its fundamental value. These markets will then follow a random walk pattern which reflects the new information that becomes available over time. Fama then introduces different degrees of efficiency with which we can characterise a market in line with how quickly it responds to the integration of relevant information into the price. Fama lists three gradations of market efficiency: the weak form; the semi-strong form; and the strong form. The weak form is a market in which prices on publicly traded assets already contain all available information at any moment in time; the semi-strong form adds to the weak form by adding that markets adjust instantaneously to new information; finally, the strong form is a market that includes in its prices 'hidden' or 'insider' information (Fama 1970, Pp383). Shiller (2003) notes that in order for the EMH to hold market participants make 'optimal forecasts'.

The fundamental principle of optimal forecasting is that the forecast must be less variable than the variable forecasted. Any forecaster whose forecast consistently varies through time more than the variable forecasted is making a serious error, because then high forecasts would themselves tend to indicate forecast positive errors, and low forecasts indicate negative errors. (ibid, p85) 
Since the empirical evidence produced by Shiller seems to indicate that asset markets are substantially more volatile than would be expected by the EMH theory, he concludes that economic agents must not be acting in line with what economists typically think of as rational behaviour. Rather investors make decisions in line with a wide variety of herd-like behaviours that are disseminated through society by powerful media and educational institutions (Shiller $2005)^{1}$. We will see that some market practitioners and academics try to develop theories that broadly fit into the behavioural finance framework.

A more developed approach to asset markets that essentially uses the EMH framework but then introduces elements which generate disequilibrium is known as the 'noise traders' approach. Stiglitz and Grossman (1980) argue that if asset markets always already integrated perfect information then no trading would take place. Therefore there must be 'noise' in the financial markets, understood as distortions that lead people to trade on false information signals. Black argues that while noise traders create more liquid markets they also introduce noise into the price of the asset (Black 1986, pp531-532). For Black, however, this does not destabilise markets, but rather means that although they are perpetually out of equilibrium they nevertheless gravitate around the equilibrium value (ibid, p533).

Other authors have created noise trader models that generate actual market instability. Delong et al (1990) lay out a model in which noise traders can cause substantial divergence of prices from their fundamental values which they say explains many aspects of why financial asset markets can display characteristics of instability. These authors say that the presence of noise traders might create uncertainty ${ }^{2}$ among rational investors who will then be reluctant to enter the market in order to drive out the noise traders (ibid., p708). In contrast to Black's formulation in which noise traders trade because they get utility from the action itself, De Long et al allow that noise traders may misprice assets based on poor information (ibid, p710).

We can thus see that the approach taken by Delong et al can be read largely as an attempt to modify the EMH. The same is true also of other authors in the noise trader literature,

\footnotetext{
${ }^{1}$ Shiller's criticisms have been dealt with by EMH theorists largely by their refocusing the debate on another aspect of the theory: namely, that individual investors cannot hope to beat the market (Malkiel, B. 2003). This does not interest us for our current inquiry because this means that the EMH is no longer a theory of how economic markets function but rather advice for individual investors - which, of course, may or may not be correct.

${ }^{2}$ Note that what Delong calls "uncertainty" is very different from what Post-Keynesian authors call "uncertainty". While the former means something like "a higher degree of measurable risk", the latter means something more along the lines of "that which cannot be known" (Davidson 1996). Whenever we use the term "uncertainty" we will be referring to the latter meaning.
} 
some of whom set up laboratory experiments to mimic such models under the assumption that such models actually reflect the real world (Cipriani et al 2005).

Active traders, on the other hand, have sought to integrate insights from behavioural finance into their textbooks and at the same time have rejected the $\mathrm{EMH}$ as a viable framework for understanding the work they do. These textbooks tend to emphasise the fact that markets can be subject to trends that may or may not reflect underlying fundamentals. They then seek to teach market practitioners how to pick up these trends in order to make money. The authors of one popular textbook, for example, write:

As opposed to the EMH, technical assumptions include the ability for prices to trend, in which case the arbitrageur, if he exists, may be overwhelmed by and may even join the consistent trend of prices away from true value. (Kirkpatrick \& Dahlquist 2006, p48)

We can view this trend in the technical literature in two ways. First of all, it is arguably important for economic theory to understand what those in the markets are doing so that economic theory does not get too divorced from what it actually happening in the real world. Secondly, and related to this, the actions of the people who read these textbooks make up a good deal of market activity. So, if market analysts believe that they should be following trends we must recognise that they could in doing so create the very trends that they believe to exist. This observation is exactly in line with George Soros's theory of reflexivity (Soros 2003), Paul Davidson's theory of non-ergodicity (Davidson 1996) and John Maynard Keynes's theory which we shall outline shortly. These theories are also similar to the approach developed by the Behavioural School. A major work of Behaviourism is Shiller (2005) which explains these trends in line with a variety of cultural, institutional and historical phenomena. The key weakness of the framework of certain Post-Keynesian economists, Soros and the Behaviourists is that it provides no real canonical framework for the analysis of financial markets as it generally focuses on attempting to track various trends in financial markets.

Among other Post-Keynesian authors we find a number of theories of financial asset pricing, many of which support one another. Michal Kalecki lays out a distinction between two fundamentally different types of markets. Kalecki argues that we should draw a firm line between what he calls 'primary' and 'secondary' markets. Primary markets are those for the likes of raw materials (copper, coal etc.) and these are characterised by fixed supply and flexible prices. Secondary markets, on the other hand, are those for manufactured goods and because 
Kalecki argues that manufacturing plants build in excess capacity in order to respond to increases in demand these markets are characterised by flexible supply and fixed prices (Kalecki 1965, Pp11-27).

For Kalecki then markets for secondary goods are largely based on the dynamics of monopoly. Price adjustments do not generally take place when demand increases; instead, quantity adjusts. Thus, for Kalecki, there is assumed to be no speculation in the markets for secondary goods because this could be brought under control by the producers themselves through a sharp increase or decrease in quantity which would reset the price at the level desired by the firms. In the market for primary goods, however, there is ample scope for speculators to profit from price speculation. Indeed, Kalecki sees this as part of the structure of these markets themselves when he writes:

With supply inelastic in the short periods, an increase in demand causes a diminution of stocks and a consequent increase in price. The initial price movement may be enhanced by the addition of a speculative element... A primary rise in demand which causes an increase in prices is frequently accompanied by secondary speculative demand. This makes it even more difficult in the short run for production to catch up with demand. (ibid, p11)

Kalecki's intuition that the key to price formation lies in whether there is the capacity and willingness to adjust quantity in response to demand rather than to allow price to adjust can tell us a great deal not only about the underlying dynamics of speculation but also about how different market structures will react to speculation.

Another approach that comes out of the Post-Keynesian school is that of Nicholas Kaldor (1939). Kaldor's theory of speculation is an attempt to supplement the analysis that Keynes laid out in his The General Theory of Employment, Money and Interest (Keynes 1936). In order to understand the former we must first understand the latter. In chapter 12 of the General Theory Keynes briefly lays out a theory of financial markets that is similar to some of those that we have seen above in that it views these markets as being based primarily on expectations which overlaps with the Behavioural theories laid out above. Keynes writes:

[P]rofessional investment may be likened to those newspaper competitions in which the competitors have to pick out the six prettiest faces from a hundred photographs, the prize being awarded to the competitor whose choice most nearly corresponds to the average preferences of the competitors as a whole; so that each competitor has to pick, not those faces which he himself finds prettiest, but those which he thinks likeliest to catch the 
fancy of the other competitors, all of whom are looking at the problem from the same point of view. It is not a case of choosing those which, to the best of one's judgment, are really the prettiest, nor even those which average opinion genuinely thinks the prettiest. We have reached the third degree where we devote our intelligences to anticipating what average opinion expects the average opinion to be. And there are some, I believe, who practise the fourth, fifth and higher degrees. (Keynes 1936, Chapter 12, V.)

Kaldor builds on this insight by laying out a simple model in which there is some degree of what he calls 'speculative stocks' - by which he means stocks of an asset held for the purposes of speculation - standing ready to respond to potential price changes. He argues that under certain circumstances this speculation can have a stabilising effect on the market as a whole because it will allow producers to 'hedge' against the future. If, however, the speculative impulse overtakes the market then speculation can have an extremely distortionary effect on the market as a whole. Kaldor measures these potentialities with two different variables; the first he calls the 'elasticity of speculative stocks' and the second he calls the 'elasticity of expectations'.

The elasticity of speculative stocks is basically the potential amount of stocks that can be held at any given time by speculators. As it approaches zero it means that there are fewer and fewer speculators standing by ready to absorb the asset and thus a lesser effect of speculators on the market. As it approaches infinity it means that the market becomes wholly speculative in that all of the assets are absorbed into speculators' stock-holdings (Kaldor 1939, p7). The elasticity of expectations, on the other hand, is the amount by which the expectation of future price increases rise or fall with respect to changes in the current price. Thus the price in speculative markets is determined by the amount of potential speculative stocks in existence and the degree to which speculative expectations change in response to a price increase (ibid, p9).

Kaldor's theory can thus be seen as somewhat ambivalent. He allows that markets may be pushed out of equilibrium by speculation but at the same time assumes that if this speculation is of certain 'hedging' character that it will increase stability in the market. We might almost say that Kaldor's theory belongs with those theories grouped under the noise trader heading; his intentions in the paper indicate that he was concerned to escape the assumption of market equilibrium rather than to enforce it.

A more recent paper that takes a similar line of inquiry as Kaldor's is Beja and Goldman (1980). While the paper is written in the tradition of the EMH it seeks to examine short-term moves away from equilibrium and the dynamics that might be generated by such moves. In particular the paper examines what might happen if investors follow trends that then generate 
the very trends that they perceive to be occurring. The paper is similar to Kaldor's in that it allows that speculators might move the market away from its equilibrium and that the main factors determining this are the level of speculative activity in the market and the extent to which the expectations of speculators play a role in price formation. Beja and Goldman's paper is particularly unusual in that it comes from a school of thought that usually considers markets to generate equilibrium even in the short-term and yet it examines in detail the effects that speculation might have on moving markets out of equilibrium without considering this due to some 'noise' or temporary blindness, but rather due to the dynamics of the market itself.

\subsection{Empirical Literature}

There is a large amount of empirical literature on the pricing of financial assets. For this reason we will here only posit one case and try to draw out the theoretical frameworks used to understand the pricing process. We have chosen the case of the oil market in the 2000s and 2010s because an interesting debate has sprung up in the literature as to whether or not speculation in futures contracts is driving the spot price of oil. This example is enlightening because it illustrates how a physical asset might fall subject to a means of pricing that is very far from the standard textbook market equilibrium presentation.

Davidson argues that there has been substantial speculation taking place in the oil futures markets since the early 2000s and this has been driving the spot price (Davidson 2008). The mechanism by which Davidson believes that speculation is taking place is that of 'user cost'. If a producer thinks that they might be able to sell their product for more in the future than they can in the present they might hoard that product or restrict its supply. This restriction of supply then drives the price of the product up and the producer realises the additional profit (ibid, p115). Davidson argues that such a user cost dynamic is at play in the oil market during the period discussed and the expected future price is being driven by the market in futures contracts which, in turn, is being driven by speculation. Thus a self-reinforcing spiral builds up where higher futures prices lead to higher spot prices which then give rise to higher expectations of futures prices which in turn become self-fulfilling (ibid, p116). This dynamic also ensures that any real shocks to the market - such as geopolitical shocks - are vastly exaggerated through the speculative process.

Such a view of how the market process works draws on Davidson's previous work on what he calls 'non-ergodicity'. Davidson argues that financial markets, such as the market for 
oil futures, can only price in risk properly in an ergodic environment - that is, an environment in which the future mirrors the past (Davidson 1996). In a world of true uncertainty where probabilistic risk cannot be used to properly assess possible future outcomes market dynamics become processes that actively play a role in setting prices and instead of a world of perfect market equilibrium we get "an uncertain, nonprobabilistic, creative economic external reality" (ibid, pp492-492). This is a view also taken by Soros, who also argues that market processes are not neutral - they are 'reflexive' - and have effects of prices which tend to push them out of equilibrium (Soros 2003, pp41-46). Davidson's views fall in line with a broadly Post-Keynesian or Behaviourist approach to financial markets as were laid out in the literature review ${ }^{3}$.

The mechanism laid out in Davidson's paper is also endorsed in a staff report given to the US Senate by the Permanent Subcommittee on Investigations of the Committee on Homeland Security and Governmental Affairs (Senate Staff Report 2006, p2-3). It was also put forward by hedge fund manager Michael Masters in a 2008 testimony to the Senate Committee on Homeland Security and Governmental Affairs (Masters 2008). This mechanism is also endorsed by economists from the St. Louis Federal Reserve who use advanced econometric techniques to estimate that speculation is the second most important factor driving oil prices after market fundamentals (Juvenal \& Petralla 2012). Juvenal and Petralla note that the Federal Reserve Chairman at the time of writing their paper, Ben Bernanke, also argued that such a mechanism could play a major role in the setting of oil prices (Bernanke 2004).

Although these authors, in contrast to Davidson and Soros, seem to lack a consistent ontological argument that would account for such a speculative effect on the price of a real asset, they nevertheless seem to endorse an identical viewpoint when faced with real world problems. For example, Bernanke and Gertler (2001) consider how monetary policy might affect asset price bubbles but nowhere in their paper do they consider why such bubbles might occur or what this might mean for broader macroeconomic theorising. This will prove to be interesting in what follows as it will lead to the broader question as to whether such instances of speculation are indeed anomalies or whether they are fundamental processes in markets for financial assets which need to be adequately theorised. In their empirical work, however, the

\footnotetext{
${ }^{3}$ Although it should be said that Davidson is probably closer to the Behaviourists than to the Post-Keynesian modellers for the reason that the latter do not truly hold to a non-ergodic view of markets as they continue to assume an underlying market equilibrium process. This will become clearer in the second chapter.
} 
above authors seem to have integrated elements of Behaviourist theory without explicitly stating this.

Fattouh, Kilian and Mahadava provide a survey of the literature on oil price speculation in which they conclude that the case for speculation driving the oil price is weak (Fattouh et al 2012). They survey a good deal of literature from the perspective that the oil market is, to a large degree, efficient and speculation is playing no role in driving prices. Their underlying theoretical framework seems to fall broadly in line with the EMH argument. This is especially evident when they reinterpret the empirical evidence of Singleton (2012) to be indicative of "frictions in the processing of information" (Fattouh et al 2012, p12). This falls in line with some of the theoretical work these authors have undertaken in the past. Fattouh (2011) argues that the reason for the increase in volatility in the oil market since prices began to rise significantly in the early 2000s is because market participants are concerned that there is an insufficient elasticity of supply to accommodate increases in demand. This reflects the view that markets are largely processing information efficiently and price increases are coming from supply and demand fundamentals. Again, this is largely in line with an EMH interpretation that does not even take 'noise' to be disruptive as laid out in our theoretical section.

In summary, we have seen that some authors argue that financial market actors through speculation can have substantial effects on the price of assets that removes them from their market equilibrium position. The case made by these authors, who can be classified as coming from a Post-Keynesian or Behaviourist position, is essentially that expectations play a significant role in these markets and that these can drive the price of the underlying asset from its fundamental value. Finally, they argue that those who produce the underlying asset may increase or decrease production in line with these expectations which then has an effect on the price of the underlying asset, together with a reinforcing effect on the expectations that set the speculative process in motion. Those authors who disputed that speculation was playing a role in oil prices argued that these prices were being driven by supply and demand fundamentals. They argued that as information becomes more difficult to interpret this may increase volatility, but it does not fundamentally affect the market price. These authors may be classified as belonging to the EMH or "efficient markets" tradition that we surveyed earlier in the literature review. 


\subsection{Summing Up}

In the next section we will explore the tension between some of the approaches that we have examined above. The tension arises from the fact that the theoretical outlines that we examined above tend to rely on some notion of market equilibrium, while the more ontologically oriented positions tend to emphasise the role of expectations. These, we will argue, are inherently in conflict with one another and in order to form a theoretical structure that truly integrates expectations we must do away with the notion of market equilibrium.

\section{THE STRUCTURE OF MARKET EQUILIBRIUM}

Despite being one of the most widely used concepts in economics, market equilibrium is not typically discussed in any sustained manner apart from at the beginning of introductory textbooks. The only other place that we find such discussion is in the very early theoretical literature. Thus the only way to approach the concept is to lay out how it is conceived in popular textbooks and in the very early theoretical literature.

One of the most popular textbooks of the $20^{\text {th }}$ century - Samuelson and Nordhaus's Economics - lays out a firm definition of market equilibrium. Samuelson and Nordhaus write:

What is a market equilibrium? It represents a balance among all the different buyers and sellers. Households and firms all want to buy or sell certain quantities depending upon the price. The market finds the equilibrium price that simultaneously meets the desires of buyers and sellers. Too high a price would mean a glut of goods with too much output; too low a price would produce long lines in stores and a deficiency of goods. Those prices for which buyers desire to buy exactly the quantity that sellers desire to sell yield an equilibrium of supply and demand. (Samuelson \& Nordhaus 1995, p24. Emphasis in original.)

The idea of market equilibrium is based on the familiar intersection of the supply curve and the demand curve. This is also the view put forward by more recent textbook writers (Varian 2010, p8).

In the early theoretical literature there is a slight divergence of opinion on how market equilibriums work. In the Marshallian tradition it is assumed that quantities adjust; thus if the demand price is higher than the supply price, the supply of the good will be increased as the producers have a price incentive to do so (Marshall 1890, p287). In the Walrasian tradition it is thought that price rather than quantity adjusts; thus, it is thought that if the quantity supplied outstrips the quantity demanded the price will fall in response (Jolink \&Van Daal 1993, pp9- 
10). Apart from this difference, however, the market equilibrium analysis for both thinkers rests on the idea of the supply and demand curves. The familiar case of the supply and demand curves that make up the heart of market equilibrium analysis can be seen in Figure 1.1 below.

Figure 1.1: Standard supply and demand model

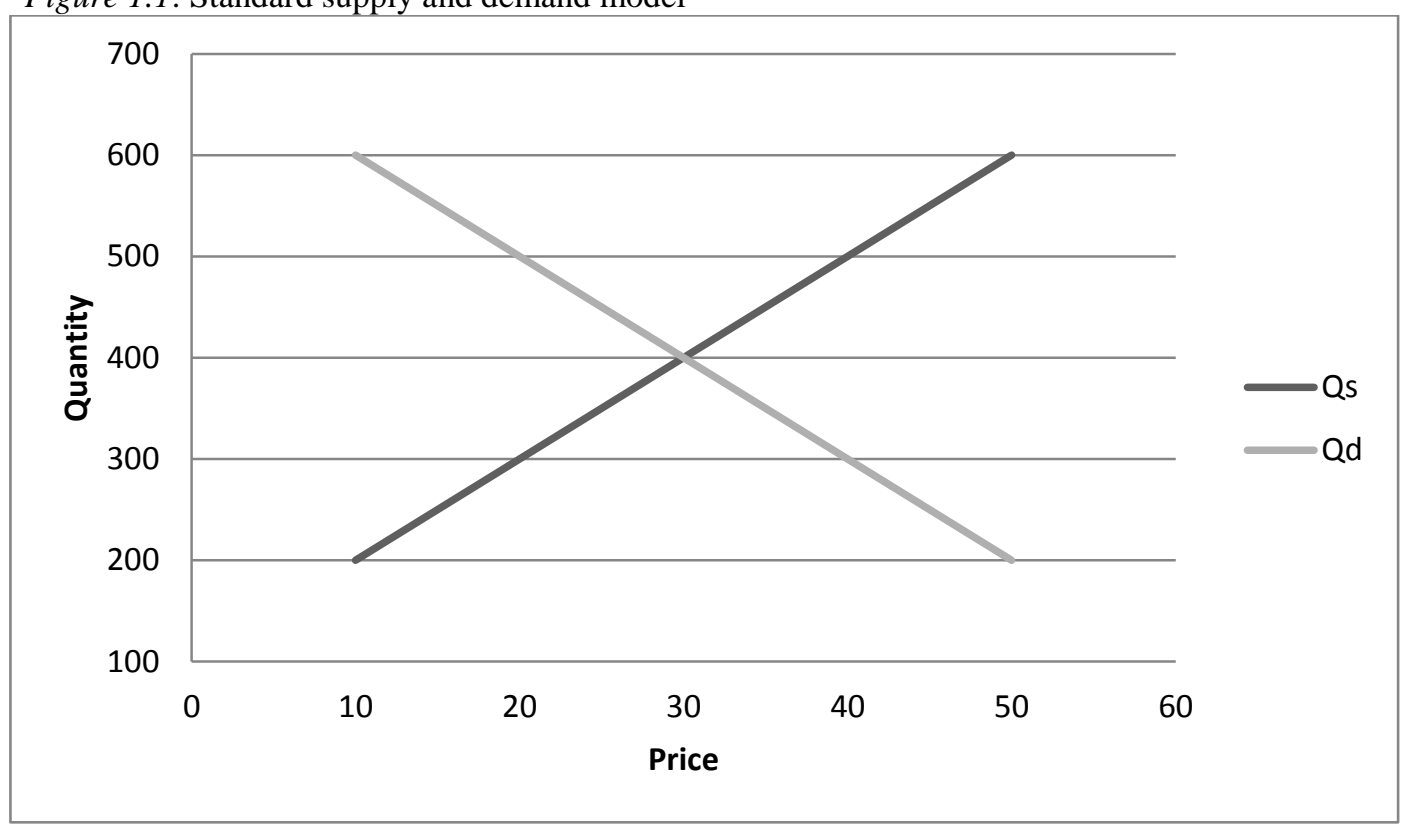

Whether we follow Marshall, and think that the quantity adjusts, or Walras, and think that the price adjusts, either way we arrive at the same conclusion: the curve representing the quantity supplied, $Q s$, slopes upwards, while the curve representing the quantity demanded, $Q d$, slopes downwards. It is at their point of intersection that we obtain a market equilibrium pricequantity relationship.

\subsection{Incorporating Expectations}

Joan Robinson points out that this idea is based on the mechanical metaphor of a scales tipping due to having more weight placed on one side but which is nevertheless tending toward a steady-state position (Robinson 1956, p57) and that the early theorists had this metaphor in mind is confirmed by reading them in the original (Marshall 1890, p269). Robinson points out, however, that the notion of market equilibrium can be problematic when used to describe economic processes that take place in historical rather than logical time and are subject to decisions undertaken under conditions of uncertainty. Robinson writes: 
[We cannot] apply the metaphor of a balance which is seeking or tending towards a position of equilibrium though prevented from actually reaching it by constant disturbances. In economic affairs the fact that disturbances are known to be liable to occur makes expectations about the future uncertain and has an important influence upon any conduct (which is, in fact, all economic conduct) directed toward future results. For instance, placement [i.e. financial asset] owners (and their professional advisers) are always on the look-out to buy what will rise in value. A belief that a particular share is going to rise causes people to offer to buy it and so raises the price... This element of 'thinking makes it so' creates the situation in which a cunning guesser who can guess what the other guessers are going to guess is able to make a fortune. There are no solid weights to give us an analogy of a pair of scales in balance. (Robinson 1956, p59).

Robinson's example appears to disturb the idea that markets can be represented in the manner presented in Figure 1.1 because such a presentation does not take into account the possible influence of expectations of future price dynamics. If we include the expectations that Robinson discusses the entire framework breaks down. In Figure 1.2 and Figure 1.3 we have laid out two supply and demand graphs that include upward-sloping demand curves, reflecting the fact that in certain markets as price increases and agents expect further price increases they demand more of the good or asset.

Figure 1.2: Modified supply and demand model with an upward-sloping demand curve where the slope of $\mathrm{Qs}=$ the slope of $\mathrm{Qd}$

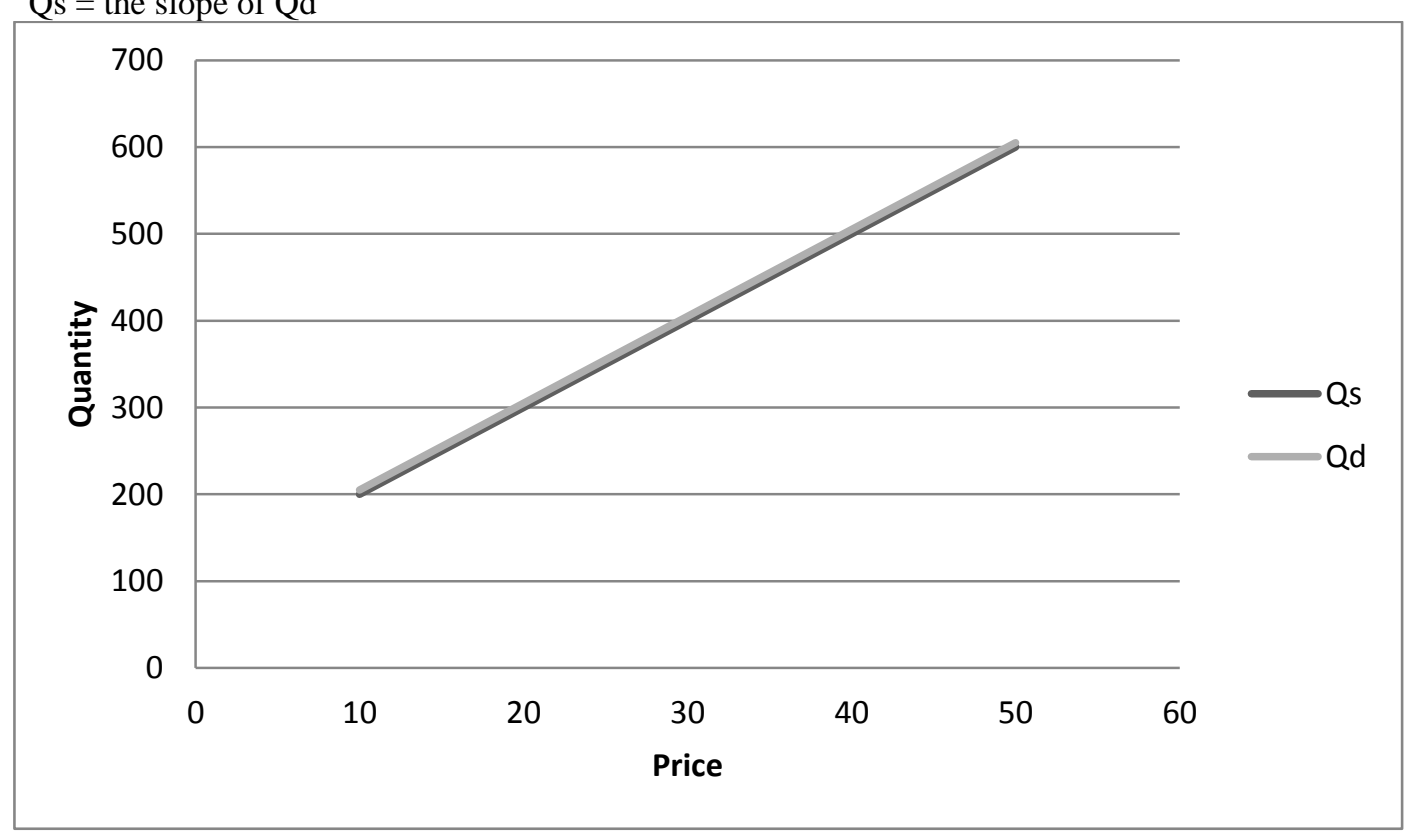


Figure 1.3: Modified supply and demand model with an upward-sloping demand curve where the slope of Qs is < the slope of Qd

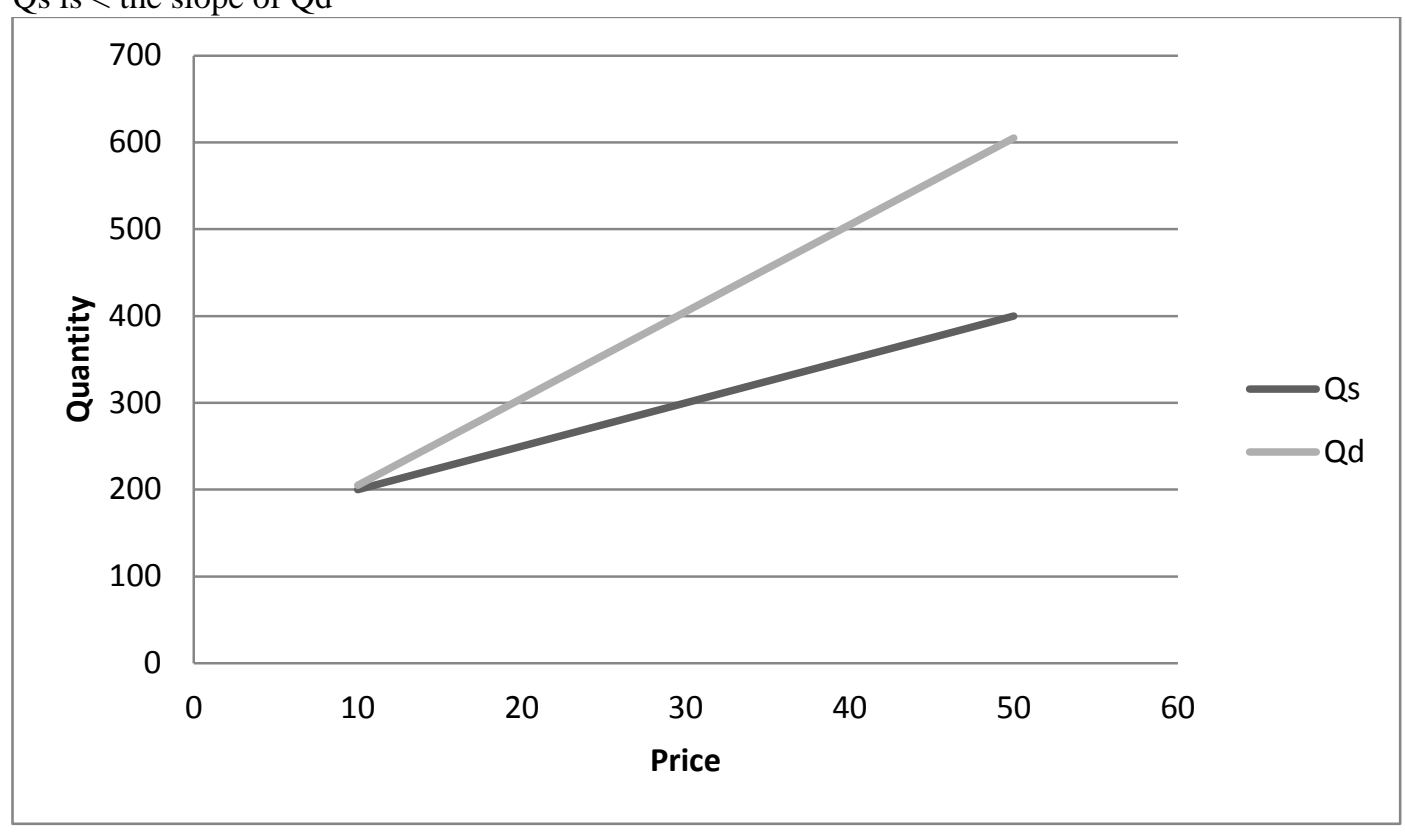

In both of these charts there is no stable Walrasian equilibrium ${ }^{4}$. In Figure 1.2 there are an infinite number of equilibrium points, while in Figure 1.3 there is a single unstable equilibrium point. It is clear that when we incorporate expectations into the theory it becomes useless. Thus the only way to incorporate such expectations is to do so exogenously. We might do this by shifting the demand curve to represent a shift in expectations. We can see this in Figure 1.4 below.

\footnotetext{
${ }^{4}$ Since the markets Robinson discusses and those that we are interested in are those in which price rather than quantity primarily adjusts, we must consider these graphs from a Walrasian rather than a Marshallian perspective.
} 
Figure 1.4: Standard supply and demand model with an exogenous shift in expectations

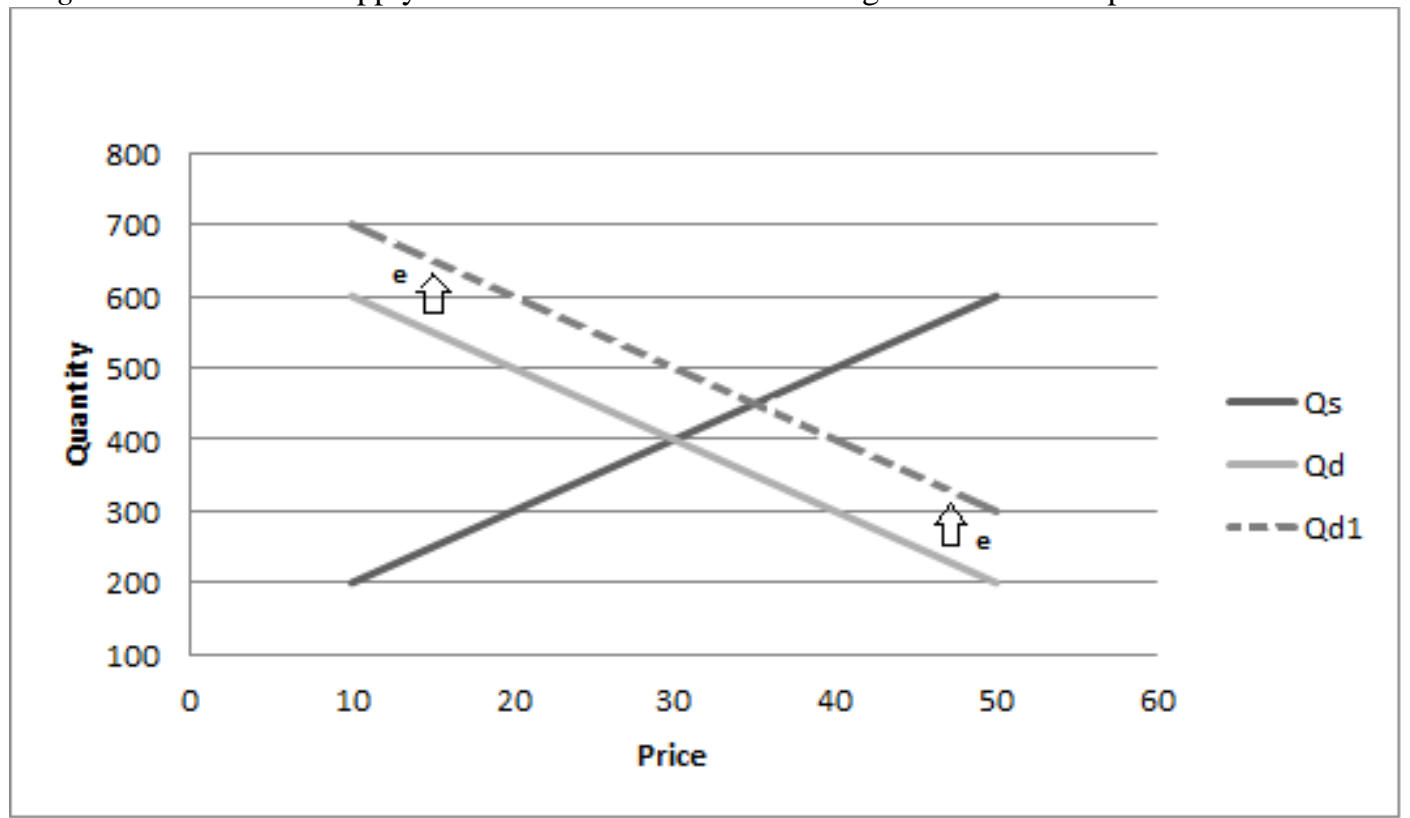

As we can see, the framework can incorporate expectations only if we include them exogenously. This, however, is problematic because it detracts from the model's ability to say anything meaningful about expectations. If we agree with Robinson that expectations play an extensive and important role in certain markets then their inclusion only as an exogenous variable resembles what the philosopher of science, Imre Lakatos, called an 'ad hoc theory' representative of a degenerating research program - that is, the addition to the theory is ad hoc in the sense that it does not allow us to explore in more detail the nature of markets with inbuilt expectations, but rather seeks to hold intact a theory that is faced with a phenomenon alien to its internal workings (Lakatos 1978, pp32-34).

This raises a broader question about the market equilibrium presentation itself with which we will be able to confront the theories we discussed in the theoretical section of the literature review: does the market equilibrium presentation seek to provide us with a framework that can make tangible predictions or provide relevant insights about market outcomes or is it simply a largely arbitrary presentational method that can be updated with exogenous conditions should these arise in real-world circumstances?

\subsection{Teleological Versus Presentational}

Another way in which we can express the same problem is to inquire into whether or not a given use of market equilibrium theory is teleological or merely presentational. Wessen (1998) has 
noted that much of marginalist economics relies on what he refers to as the 'teleological impulse'. This is the idea that there is some final goal inherently embedded in economic processes and that these processes will inevitably lead to this final goal provided they are not purposely impeded. In particular he points to the notion of optimal long-run market equilibrium.

Wessen's idea of a teleological impulse is the same as the idea that markets will always converge to equilibrium at some point in time and thus the structure of market equilibrium analysis is not simply an ex-post presentation of what has already happened in a given market but instead an ex-ante description of what will happen.

As we have already shown in Figures 1.2 and 1.3 above, if we take Robinson's expectations into account and include them in the model there is no stable Walrasian equilibrium point and thus the framework breaks down completely. If we, however, include expectations as an exogenous variable that shifts the demand-curve, as shown in Figure 1.4, then Robinson's expectations can indeed be accommodated. It is clear, however, that while the models laid out in Figures 1.2 and 1.3 sought to include the reality of expectations in order to study them and even make relevant insights or predictions about what might actually happen in a market - thus, in Wessen's language they were structured teleologically - in the model laid out in Figure 1.4 expectations are introduced in an ad hoc manner as merely a means to preserve the notion of a stable Walrasian market equilibrium laid out as a teleological end-point in Figure 1.1 .

The problem with such a non-teleological view of market equilibrium is that it is, as we have already pointed out, characteristic of a degenerating research program. If expectations play an important role in certain markets and including these expectations overthrows the framework we are using, the question arises as to why we are using this framework in the first place. It seems that what is being done in the model laid out in Figure 1.4 is that we are attempting to keep the teleological structure of market equilibrium intact - i.e. the one laid out in Figure 1.1 that shows a tendency toward a fixed, teleological market equilibrium outcome - while at the same time adding a non-teleological, ad hoc condition to accommodate important features of the market being studied (i.e. expectations). If the reality of certain markets cannot be captured within a framework and must be introduced in an ad hoc manner a better approach is probably to create a framework that can accommodate the reality of these markets.

\subsection{Market Equilibrium in Theories of Financial Markets}


The first theoretical conception of financial asset markets that we studied in our literature review was the Efficient Markets Hypothesis (EMH). We saw that the EMH assumes that prices in financial markets follow a random walk which represents the information coming available to the market at any given moment in time (Samuelson 1965). The key assumption here is that an efficient market is one in which the information coming available is reflected perfectly in the price or, as Fama puts it: "A market in which prices always 'fully reflect' available information is called efficient.”(Fama 1970, p383).

The random-walk process in such markets is teleological in the sense that, although the price trajectory of these markets cannot be known in advance, we can nevertheless say that such markets are efficiently processing information. This leads to a positive conclusion that these markets will not be prone to any substantial instability and also that individual investors will not be able to beat these markets over any extended period of time (Malkiel 2003). This fits perfectly with Wessen's (1998) claim that certain marginalist theories are teleological because they assume a fixed long-run market equilibrium end-point. In this regard the underlying metaphysical structure of the EMH is identical to the simple market equilibrium approach laid out above, i.e. it is teleological.

It should also be seen as an extension of the basic structure of market equilibrium we laid out above theoretically. Rather than generating a downward-sloping demand-curve by assuming fixed preferences and diminishing marginal utility on the part of consumers (Samuelson, 1995), the EMH assumes that investors have access to perfect information and incorporate this into their decisions to purchase an asset.

Implicit in the perfect information assumption of the EMH is that so-called irrational expectations will never dominate in the marketplace and that all purchases and sales will be reflective of the underlying information and thus subject to the constraints of the standard market equilibrium model as laid out above.

We can translate these relationships into a familiar framework by simply taking our standard supply and demand graph as laid out in Figure 1.1, replacing 'quantity' with 'risk' and 'price' with 'expected return' or 'yield' and switching the direction in which the Qs and Qd lines slope - i.e. the Qd curve becomes upward-sloping and the Qs curve becomes downwardsloping. This can be seen below in Figure 1.5. 
Figure 1.5: EMH information equilibrium in a supply and demand framework

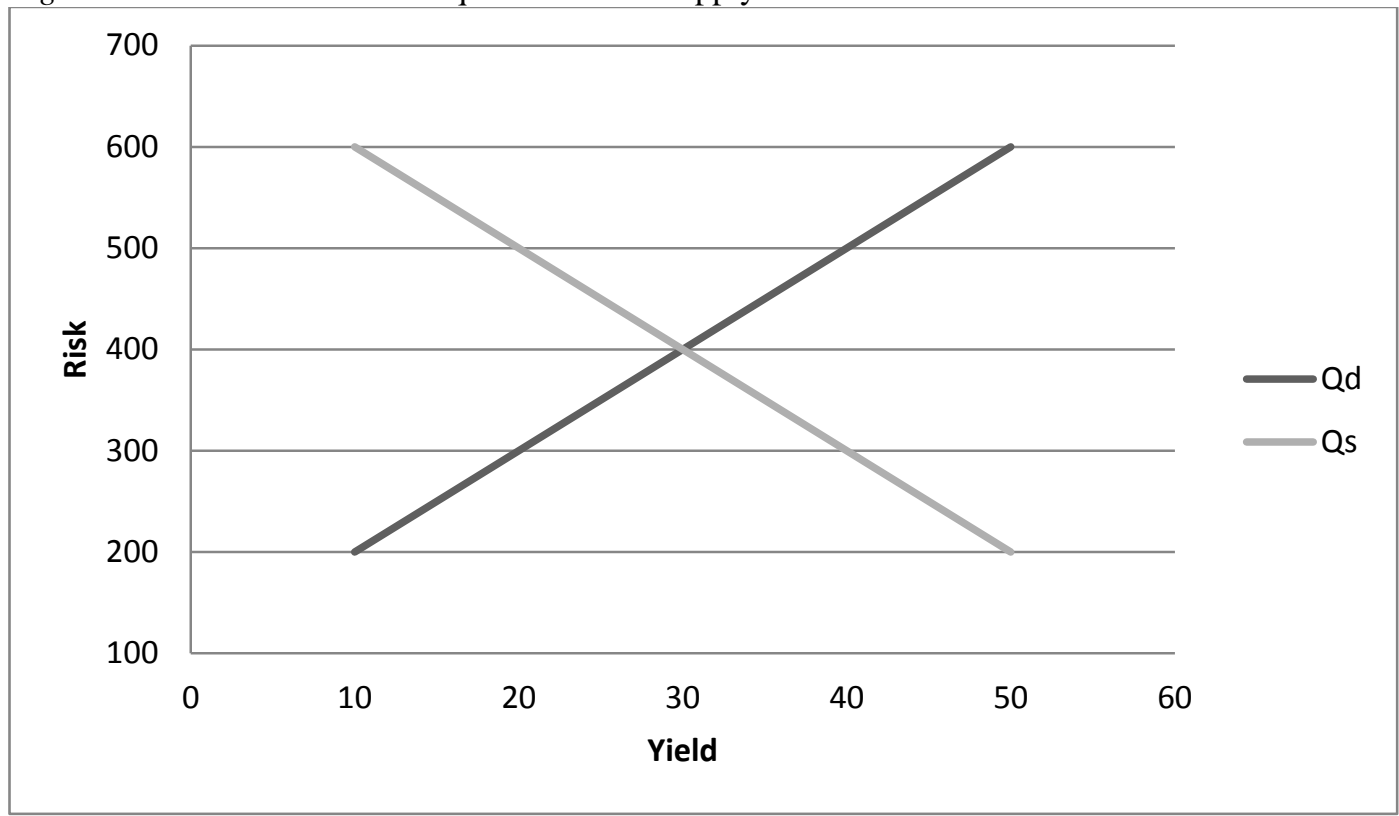

The manner in which we should interpret this is as follows. The downward-sloping supply curve indicates that those issuing the asset will issue a large amount of the asset if the yield is low and the risk of the asset high while if the yield is high and the risk of the asset low the issuer of the asset will issue less of this asset. The upward-sloping demand curve indicates that at a low level of risk only a low yield will be required for investors to purchase the asset while at a high level of risk a high yield will be required for investors to buy the asset. The astute reader will note that the upward-sloping demand curve is identical to the Security Market Line (SML) in popular Capital Asset Pricing Model (CAPM) used in financial economics to determine the fair value of an asset, thus further buttressing our point that financial asset pricing is currently based on a market equilibrium model. Finally, we should note that the point of intersection of the two curves represents an equilibrium at which investors have priced in all risk correctly and those issuing assets have issued just enough to meet this equilibrium demand; thus the equilibrium point is precisely the EMH equilibrium of perfect information balancing noted above given the additional assumption that those entities supplying assets try to maximise the riskiness of the asset issued while minimising the yield. Understood in this way we can clearly see that the perfect information equilibrium of the EMH translates seamlessly into a familiar market equilibrium supply and demand model.

The next theoretical conception of financial asset markets that we examined was the 'noise trader' theory. This approach is essentially based on the EMH approach but makes a 
qualification that some amount of 'noise' must exist that disturbs financial markets from their equilibrium position due to the fact that information is not being processed in a perfect manner. Such a conception of markets could lead to the conclusion that they do not tend toward a market equilibrium position. Black, however, takes an explicitly teleological view insofar as he views these markets as "gravitating" toward their perfect information equilibrium position in the medium to long-run (Black 1986, p531-532).

Delong et al (1990) build noise trader models that allow for substantial divergence of the market from its equilibrium position due to the presence of noise traders. Underlying their framework, however, is the assumption that if it were not for the existence of these noise traders, more rational traders would move the market back to its equilibrium position; thus the exogenous introduction of noise becomes synonymous with the exogenous introduction of expectations in Figure 1.4. In light of the above discussions of teleology this produces similar problems to those that we laid out above with respect to positing a non-teleological view of market structure while nevertheless maintaining the market equilibrium perspective. Such attempts beg the question as to why, if we admit that markets need not converge to an equilibrium position, should we posit the existence of market equilibrium as a sort of general case while positing the existence of substantial divergence from equilibrium as merely a particular case. As in the simpler case laid out above in Figure 1.4, the noise trader models raise the objection that they are defending the market equilibrium structure by positing the case of divergence from equilibrium in an ad hoc manner, thus giving rise to a degenerating research program.

Some Post-Keynesian authors also assume such an equilibrium position for markets as a sort of general or endogenous case, while speculation is simply a particular or exogenous case. This is manifest, for example, in Kaldor when he argues that speculation would tend to stabilise the market unless speculative expectations get out of control (Kaldor 1939, p7) - an argument that would fit perfectly well with the noise trader theorists. It is also manifest in Beja and Goldman (1980) when they write:

Satisfied as we may be with the overall efficiency of the market system and with the tenets of the perfect market model, we all viscerally know that were we down on the market floor we would certainly react to a multitude of apparent price discrepancies. (ibid, p235) 
For these authors the framework that they lay out is to be understood as a short-period framework to be used to analyse temporary divergences from equilibrium - and thus as a special case of distortions in an otherwise teleological market tending toward a stable market equilibrium.

The case of Beja and Goldman is particularly interesting because, although they seek to situate their work in the broader tradition of assuming convergence toward market equilibrium, their actual framework contains no real market equilibrium conditions. For this reason Beja and Goldman's work is highly suggestive of an approach that we can take that would be nonteleological in that it did not assume convergence to any fixed market equilibrium outcome.

We should take this opportunity to note the divergence here in Post-Keynesian theory and similar theories. While Davidson, Soros and Shiller hold definitively that markets do not tend toward any market equilibrium outcome, the other Post-Keynesian authors like Kaldor appear to concede that at some level they do. The only reason that we do not include the likes of Kaldor with the noise trader theorists is because, at some level he does seem to recognise nonteleological behaviour in markets and seems to aspire to include such behaviour in their models. Kaldor was, in a sense, aspiring to create non-teleological models of market processes, while Davidson, Soros and Shiller are content to simply assume non-teleological market processes that either need not or cannot be modelled. It will be our goal in what follows to try to build a bridge between these two approaches in that we seek to build a formal theoretical framework but insist on taking the role of expectations seriously and thus doing away altogether with the notion of market equilibrium.

\subsection{An Alternative Non-Market Equilibrium Structure}

In the third part of this paper we aim to lay out a general theory of prices that does not rely on the idea of market equilibrium, but which can nevertheless generate it as a special case. Ideally, such a theoretical framework will prove far more flexible in its application to empirical data and will stay true to how prices are actually formed in the real world.

We take our bearings here from Post-Keynesian authors who wrote that the Keynesian revolution in macroeconomics produced a framework that did not require the idea of market equilibrium. Kaldor laid out in extensive detail why the idea of market equilibrium was fundamentally wrong (Kaldor, 1985) while Godley showed how a system of Keynesian expenditure equations, together with equations representing the banking system can be used to 
model the economy without reference to the notion of market equilibrium (Godley, 1997). Such a system of equations, Godley showed, only needed the notion of a stock-flow equilibrium in order to be solved.

The shift can be traced back to the beginning of the Keynesian revolution and it explains why in Neo-Keynesian and Post-Keynesian theory an economy need not tend toward a full employment market equilibrium but is instead thought to generate a certain level of activity given a certain level of aggregate demand. Prior to the publication of Keynes' General Theory (Keynes, 1936) it was assumed that the level of employment and thus output was set based on a market equilibrium between the marginal product of labour, on the one hand, and the labour supply, which reflected the amount of leisure workers were willing to forgo at a given wage, on the other. This is depicted in Figure 2.1. The level of investment was then set through a second market equilibrium process in the money market where the amount of investment was equal to the amount of saving that was undertaken at a given rate of interest. This is depicted in Figure 2.2. Together these two market equilibrium processes led to a full employment market equilibrium in which the pace of investment was dictated by the amount of income economic agents chose to save rather than consume. 
Figure 2.1: Pre-Keynesian marginalist supply and demand for labour model of wages and employment

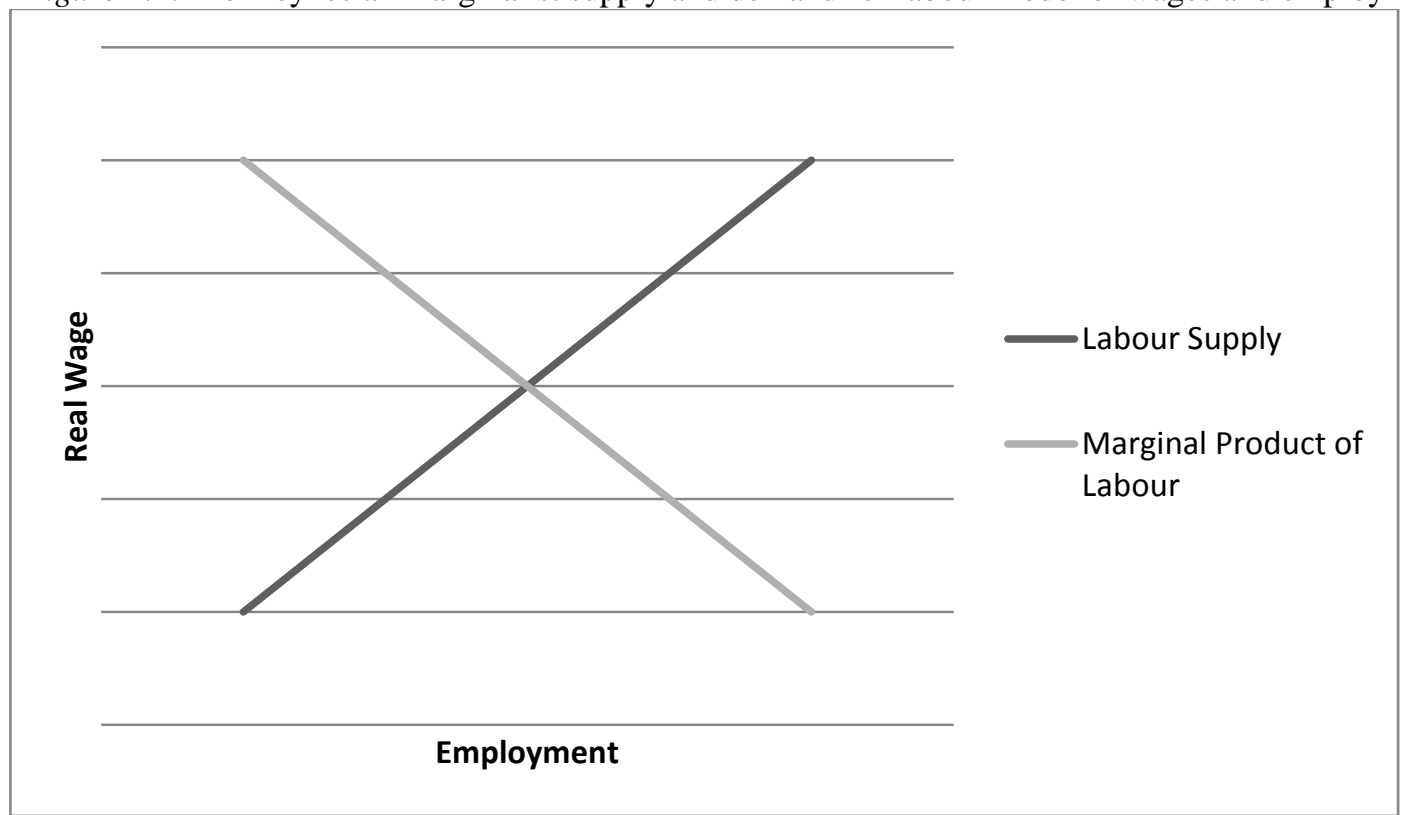

Figure 2.2: Pre-Keynesian marginalist loanable funds model of savings and investment

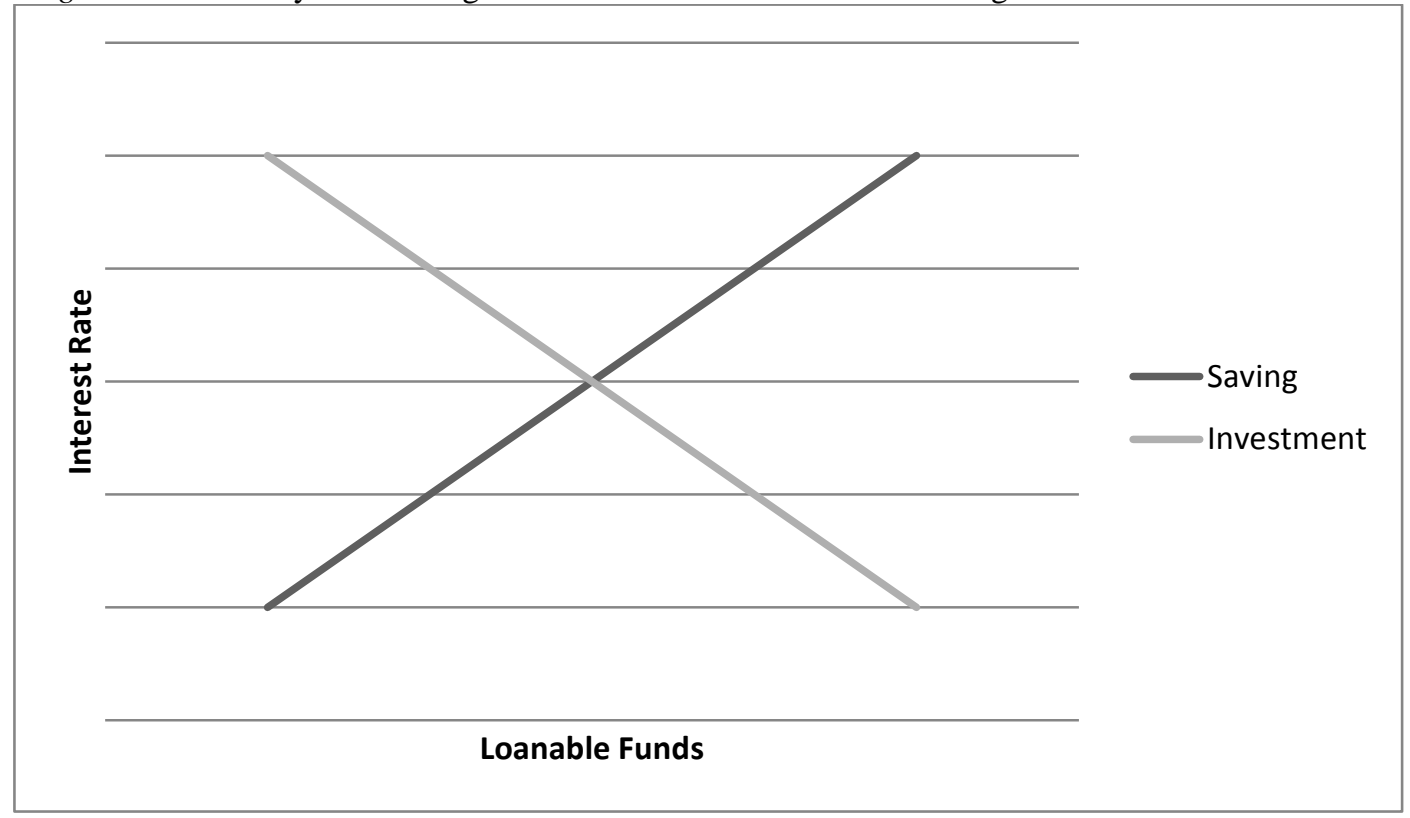

As we can see Figures 2.1 and 2.2 have an identical structure to the simple market equilibrium frameworks explored in the first sections of this paper. All these frameworks are characterised by an inverse relationship between price and quantity - whether the price of money, labour or an individual good. As we now know from our preceding analysis that both are also implicitly based on a teleological conception of the interaction of the variables. There is 
no room for any perverse movements in the supply and demand curves; in order to do so they would have to become malleable in such a way as they would no longer have any firm ex-ante predictive power and would instead become merely a means to present the empirical facts in an ex-post manner. As long as these models could be said to have any predictive or descriptive power over real-world economies it is clear that the prices - that is the price of labour and money, respectively - had to clear markets to produce a full employment market equilibrium.

After Keynes' General Theory these models were called into question and it came to be thought that the prices set on money and labour might not clear all markets and produce a full employment market equilibrium. While there are a variety of different interpretations of the Keynesian revolution, they all agree on the fact that under at least some circumstances the interest rate might not clear the money market and the real wage might not clear the labour market. Given that all the Keynesian schools agree on this point, they then all apply the concept of the Keynesian multiplier to determine what level output will reach. As we will see, the multiplier is a properly non-teleological, non-market equilibrium model of output determination because empirical variables are simply 'plugged in' and the equation produces a level of output that corresponds to these empirical variables ${ }^{5}$. For this reason we hope to base our theory of asset prices on a similar framework.

Let us now lay out very briefly the Keynesian multiplier as it is usually presented to bring out some of the structural features that are of interest for a non-teleological, non-market equilibrium theory of asset prices. In order to present the Keynesian multiplier we must first define the consumption function. The consumption function determines how much of their income economic actors in the aggregate will consume when this income is changed. It is usually written as such:

\section{$1.1 C_{t}=C_{0}+c Y_{t-1}$}

The consumption function thus includes a term for both autonomous consumption, $C_{0}$, and a propensity to consume out of income, $c$. The propensity to consume out of income is then multiplied by the income at the time of its injection, $Y_{t-1}$, and this produces the end period level of consumption, $C_{t}$.

\footnotetext{
${ }^{5}$ It should be noted, however, that while some Keynesians in the Post-Keynesian tradition fully did away with the idea of market equilibrium in their theory of output and employment others in the neo-Keynesian tradition resurrected it in the form of the ISLM diagram. This does not here concern us further, however.
} 
We can then proceed to insert the consumption function into the standard national income equation in order to get end period total income after the propensity to consume out of income has taken effect. When the consumption function is inserted into this equation we get the following ${ }^{6}$ :

\section{$1.2 Y_{t}=C_{0}+c Y_{t-1}+I$}

As we can see the total level of output/income, $Y_{t}$, is now dependent on two exogenous components, $C_{0}$ and $I$, and an endogenous variable, $c Y_{t-1}$, which is the propensity to consume out of income variable as it relates to the previous period's income/output. As we can see there is no teleological component to the Keynesian multiplier relation. The level of output/income is not set through a market equilibrium process where markets clear based on price as in the classical conception; rather what we have is what we will call in line with Godley (1997) a 'stock-flow equilibrium' where the end point equilibrium output/income is determined by the interaction between stocks and flows.

The numerical values we give the variables that ultimately determine such an equilibrium can be anything and it is in this way that the formula can be applied empirically. The formula does not seek to make any a priori ex-ante predictions about the level of income/output per se, rather it provides a means by which we might think through (and sometimes estimate) how income/output is determined in any given period. It is this structure that we will seek to replicate in our theory of asset pricing so that we can create a properly general theory of pricing that incorporates expectations in the next section.

\section{A STOCK-FLOW APPROACH TO A GENERAL THEORY OF PRICES}

The goal of this section is to lay out a non-teleological, stock-flow equilibrium theory of asset prices in particular and also prices more generally. The assumption under which it is written is that all goods in a capitalist economy fall into one of three groups. They are either: (i) pure assets, for example, a company's shares; (ii) impure assets that are part asset and part consumer good, for example, a house; or (iii) pure consumer goods, for example, a haircut.

\footnotetext{
${ }^{6}$ Note that in equation 1.2 we have assumed a closed economy with no government for the sake of simplicity of presentation. Thus, national income is determined purely by investment plus consumption. We have also ignored any effects that a rise in national income might have on investment. Such more nuanced relations can be added later to out multiplier equations without altering their fundamental structure.
} 
The approach that will be taken will attempt to provide a framework within which all three types of goods can be understood. Because two of our classes of goods have an asset component we will also be taking the role of speculation seriously. We assume that speculative demand can, in any given market, make up a substantial portion of overall demand in that market. At the end of the section we shall consider some of the most important general implications of our theory.

\subsection{General Theory of Financial Asset Prices}

In order to approach this topic we should first provisionally define what we mean by an "asset". We need not deviate from the standard economic definition of an asset in this regard. Harrison (2006) notes that the standard definition of an asset in the System of National Accounts is as follows:

The assets recorded in the balance sheets of the System are economic assets. These are defined as entities: (a) over which ownership rights are enforced by institutional units, individually or collectively: and (b) from which economic benefits may be derived by their owners by holding them, or using them, over a period of time. (Harrison 2006, p1)

Such a definition is a perfect fit for our purposes. As stated above one of the key pillars of our approach is to take into account the fact that many goods in capitalist economies have an asset component and it is a mistake to merely consider what we have termed 'pure assets' as the only type of asset class. Indeed, in light of the recent financialisation of many markets (see: Wray 2008) it is important that a theory of asset prices can encompass a wide variety of markets.

We will also be departing from standard marginalist theory in that we will not be assuming that producers/firms produce up to the point of full capacity. We undertake this departure for two broad reasons. First of all, the empirical literature on this topic over the past fifty years or more has shown clearly that this is not how firms in capitalist economies operate. Much of this empirical literature has been generated through surveying firms regarding their cost curves and it has been shown that firms do indeed operate in a largely flexible quantity, fixed price manner. A recent study by Blinder et al, for example, has revealed that only 11 per cent of US firms operate in conditions of rising marginal cost (Blinder et al 1998, p105); a condition, of course, required for a properly marginalist conception of markets to function. 
Other empirical studies over the past century have shown similar results, for example (Eiteman \& Guthrie 1953).

Our approach will be in keeping with the Post-Keynesian tradition which is well summarised by Marc Lavoie (note that he refers to as 'neoclassical' we here refer to more accurately as 'marginalist'):

Prices are not such that they equate supply and demand schedules. In a context where supply is flexible, firms do not necessarily attempt to equate demand to the normal use of capacity when they set prices. This in my opinion is what distinguishes the markets in which firms of the post-Keynesian type operate and those in which the standard neoclassical firm still makes sense. The position taken here is that these non-clearing markets are the rule whereas the clearing ones are the exception. (Lavoie 1992, p95).

The second reason that we will be undertaking this departure is because we wish to lay out a theory that can be applied to all goods, including pure assets. Clearly there is no limit to which a firm can, for example, issue shares or a central bank can issue currency. Thus it would be obviously absurd to set some sort of 'full capacity' constraint on the production of such assets.

In order to build our framework we must first redefine some of the familiar macroeconomic/national accounting identities. We do this for two reasons. First of all, to ensure that our framework can be easily integrated with any other framework that respects such identities; and secondly, to ensure that our framework is consistent with the national accounts. The first step in this process is to include demand variables for financial assets. These demand variables apply to both what we have termed pure assets and impure assets. It should be noted that the standard national income identities measure aggregate demand and national income; while this is true of the 'real' variables introduced later in our approach it is not true of the financial asset variables. These components generate only financial income and are not to be thought of as being included in, for example, measures of gross domestic product or aggregate demand.

We will begin by laying out the identities for what we have termed pure assets and then proceed to lay out our final supply and demand equation for such assets. We will then move onto impure assets and pure consumer goods. Note that the argument shall be progressing by first laying out the demand side variables and only afterwards laying out the supply side 
variables ${ }^{7}$. The first step is to lay out the basic identities of an income and expenditure approach for a closed economy.

$1.1 E_{f}=I_{f}+G_{f}$

Where $E_{f}$ is total financial expenditure; $I_{f}$ is total private financial investment; and $G_{f}$ is total government financial investment, inclusive of central bank purchases. We can then set out the income side of the equation and since income equals expenditure we can substitute.

$1.2 Y_{f}=S_{f}+T_{f}$

Where $Y_{f}$ is total financial income; $S_{f}$ is total financial saving, i.e. saving accrued from financial transactions; and $T_{f}$ are total financial taxes, i.e. taxes on financial transactions. So, since financial income equals financial expenditure then,

$1.3 I_{f}+G_{f}=S_{f}+T_{f}$

We then lay out the determinants of financial expenditure which will in turn set the price of financial assets from the demand side. We also introduce time periods in order to make our exposition clearer.

$1.4 Y_{f t}=E_{f t}=\frac{P_{f t}-p_{f t-1}}{\delta}=I_{f t}+G_{f t}$

Where $P_{f t}$ is the price on financial assets at a given time; $p_{f t-1}$ is the price in the previous time period and is representative of past expenditure flows; and $\delta$ is the price elasticity of demand understood as a value $\leq 0$ and $\geq 1$, where a higher price elasticity of demand is represented by a lower value and a lower price elasticity of demand is represented by a higher value. So,

$1.5 I_{f t}+G_{f t}=\chi \Delta P^{e} f t$

${ }^{7}$ One might think of the demand side equations, which include equations 1.1 to 1.10 , as being price equations when the supply side in any given market is fixed - i.e. when there is a vertical supply curve. 
Where $\Delta P_{f t}^{e}$ is the expected price change in the present time period; and $\chi$ is the propensity of investors to speculate on an asset with a given amount of income and is more thoroughly discussed below. Note that $\Delta P_{f t}^{e}$ incorporates the Behaviourist and Post-Keynesian assumption about expectations laid out in our first section. So, substituting equation 1.4 into equation 1.5 we get,

$1.6 \frac{P_{f t}-p_{f t-1}}{\delta}=\chi_{f} \Delta P_{f t}^{e}$

Or,

$1.7 P_{f t}=p_{f t-1}+\chi_{f} \delta \Delta P_{f t}^{e}$

Where $p_{f t-1}$ is the price in the previous time period.

Such an approach is broadly similar to that taken by both Kaldor (1938) and Beja and Goldman (1980) in that the term $\chi_{f}$ can be thought of in the as being quite similar to Kaldor's 'elasticity of expectations' or Beja and Goldman's 'average of speculator's assessment of current trends'. Another somewhat similar approach can also be found in Godley and Lavoie (2012) where they use the same term $\chi$ to denote the degree of confidence held by investors in the expected rise in the price of bonds. Such a measure is, they write, "a measure of the degree of confidence of financial investors, or a measure of the weight that household investors attribute to the validity of their expectations" (ibid, p133).

We can further break down the components of our propensity to speculate term $\chi_{f}$ into a minimum or barrier profit term and a pure confidence term. This will distinguish it from the similar functions outlined by the aforementioned authors above. The minimum or barrier profit term, $\pi_{m}$, expressed as a percentage of the expected price change, introduces the idea which will be important later on that investors will only buy and hence bid up a financial asset to the point where the spread between the expected price change, $\Delta P_{f t-1}^{e}$, and their maximum bid, ensures the minimum level of profit they deem necessary for the risk incurred in holding the asset.

\section{$1.8 \chi_{f}=\gamma_{f}-\pi_{f m}$}


Substituting equation 1.8 into equation 1.7 we get equation 1.9 which lays out the whole of the demand side of our theory of pure asset pricing.

$1.9 P_{f t}=p_{f t-1}+\left(\gamma_{f}-\pi_{f m}\right) \delta \Delta P_{f t}^{e}$

This completes the demand side of our equations. We now move to introduce a supply side into our equations. This supply-side component, as previously discussed, assumes flexible adjustments on the part of the producer of financial assets. It denotes the propensity to increase production and/or offload inventories. It should be noted that this supply-side component also reflects Kalecki's observations about fixed and flexible price markets as having different price dynamics (Kalecki 1965). Modifying equation 1.9 we get equation $1.10^{8}$.

$$
P_{f t}=p_{f t-1}+\left(\gamma_{f}-\pi_{f m}\right) \delta \Delta P_{f t}^{e}-\delta q Z_{t}^{9}
$$

Before moving on to laying out our framework for a more general theory of prices that can applied to both impure assets and pure consumer goods we will first consider how we might produce a 'closed' model and then we will lay out some real world applications of our framework in order to show its fundamentally 'open-ended' nature. In order to produce a closed model we can simply assume that previous increases assets prices are projected forward by investors as is shown in equation 1.11.

\section{$1.11 \Delta P_{f t}^{e}=\Delta P_{f t-1}^{e}$}

\footnotetext{
${ }^{8}$ It should be noted that equation 1.10 can be understood as describing either a single market for a given financial asset or all markets for financial assets. We would council that should it be used to describe a single market for a given financial asset the appropriate subscript should be included. For example, the equation for the US stock market might look like this:
}

$$
P_{U S S t}=p_{U S s t-1}+\left(\gamma_{f}-\pi_{f m}\right) \delta \Delta P_{U S s t}^{e}-\delta q Z_{U S s t}
$$

\footnotetext{
${ }^{9}$ It should be noted that equation 1.10 can be understood as describing either a single market for a given financial asset or all markets for financial assets. We would council that should it be used to describe a single market for a given financial asset the appropriate subscript should be included. For example, the equation for the US stock market might look like this:
}

$$
P_{U S s t}=p_{U S s t-1}+\left(\gamma_{f}-\pi_{f m}\right) \delta \Delta P_{U S s t}^{e}-\delta q Z_{U S s t}
$$


This simple adaptive expectations equation will produce a situation in which asset price increases self-generate and prices rise potentially to infinity until an external constraint causes either the market to level off or to crash. We stress, however, that following Keynes we should not interpret the framework laid out above as "a machine, or method of blind manipulation, which will furnish an infallible answer" but rather as a framework that provides us "with an organised and orderly method of thinking out particular problems" (Keynes, 1936, Chapter 21, III). In this light let us consider two aspects of the framework that will allow us to get an idea how it should be properly used.

Let us consider the oil market that we discussed in our first chapter. There we saw that some theorists claimed that oil producers might withhold supply in order to take advantage of speculative demand by essentially concealing their part in price rises ${ }^{10}$. In such an instance we would expect $\chi_{f} \Delta P_{f t}^{e}$ to be a positive variable while $q Z_{t}$ would either be (a) smaller in magnitude than $\chi \Delta P_{f t}^{e}$, (b) zero or (c) a negative number. We can then give differing interpretations to each case.

In case (a) the oil producers are not allowing production to match rising speculative demand but are nevertheless easing the price pressure to some extent. This might be an instance in which the oil producers wanted to take advantage of the speculative demand pressures in order to profit from the rising prices but recognised that if prices increased too much real demand might be affected. In case (b) we see that oil producers are fully taking account of the rising speculative pressures. While in case (c) they are actually cutting production, presumably because they are using the speculative demand pressure as cover to raise prices even more.

Now contrast that hypothetical scenario with what might happen in the government bond market should there be a substantial flight to safety and subsequent speculative episode in government bonds. As the variable $\chi_{f} \Delta P^{e}{ }_{f t}$ rose the central bank would engage in offsetting bond sales through open market operations in order to defend their target rate of interest which would fall in inverse proportion to how much the price of the bonds rose $\mathrm{e}^{11}$. Thus the central bank would raise the variable $q Z_{t}$ in order to try to match and offset the rise in $\chi_{f} \Delta P_{f t}^{e}$.

\footnotetext{
10 Oil, of course, is not a pure asset but rather an impure asset. Nevertheless, we can discuss speculation and producer's creating artificial scarcity perfectly well with the framework that we have designed for pure assets.

${ }^{11}$ Note that, in this example, while the central bank is not actually the "producer" of government bonds which is the task of the Treasury - it is nevertheless true from a functional point-of-view that central banks effectively hold the "inventory" of government bonds and release these onto the market through open market
} 
As we can see, the theory holds up well when faced with two entirely different market scenarios: one in which the producer seeks to take advantage of speculative demand in order to accrue higher profits, the other in which the effective producer seeks to defend a price target. In both cases the markets may be conceived of, along aforementioned Post-Keynesian lines, as 'fixed price markets' because we assume that each producer has enough inventory/productive capacity to 'break' or accentuate any speculation or price changes that may take place, but our theory allows us to understand and elaborate on precisely what is going on in those markets at any given point in time ${ }^{12}$.

We can further expand on this basic model by adding other closures if we can find empirical justification for doing so. For example, consider that the market for US shares tends to respond positively to any fall in the central bank interest rate. In the market in which interest rates were not having any effects on expected price changes $\Delta P_{f t}^{e}$ was entirely set in line with expectation, $e$, which were positively correlated with $\Delta P_{f t}^{e}$. This is shown in equation 1.12 below which is, of course, a tautology implicitly assumed in the equations above.

\section{$1.12 \Delta P^{e}{ }_{U S S t}=f\left(e^{+}\right)$}

In order to include the interest rate, $i$, as a negatively correlated variable to expected prices changes, $\Delta P^{e}{ }_{f t}$, however, we can now just include this in the function as is shown in equation 1.13 .

\section{$1.13 \Delta P^{e}{ }_{\text {USSt }}=f\left(e^{+}, i^{-}\right)$}

We can imagine a different market in which a change in certain variables has certain effects. There is, of course, no general rule for this and such markets must be taken on a case by case basis. The advantage of our approach is that such effects can be integrated quite cleanly

operations in order to set the interest rate. We are drawing here, of course, on the Modern Monetary Theory literature and the endogenous money literature. For example, see: (Wray 1998, p97-119) and (Lavoie 1992, p149217).

${ }^{12}$ We can, of course, also imagine markets in which speculative demand can outstrip the ability of the supply-side to adjust. This is not generally recognised in the Post-Keynesian fix-price theory. A good empirical example of this would be when George Soros 'broke' the sterling's peg to the European Exchange Rate Mechanism (ERM) in 1992 by selling so much sterling that the central bank ran out of foreign currency inventory and could not continue to defend it. All of this can, of course, be introduced in our theory by lowering the value of the production/inventory variable, $q Z_{t}$. 
and simply by making the expected price change, $\Delta P_{f t}^{e}$, a function of whatever this variable or these variables might be.

The question as to whether the variables laid out in equations 1.4 to 1.10 should be understood as nominal or real is also an empirical one. In many financial markets, such as bond markets, investors will always price in expected inflation into their expectations and in such cases we can use inflation adjusted estimates rather than simple nominal measures. In the case of other assets, for example consumer purchases of vehicles, it is probable that while consumers will price in depreciation - which would lead to a negative $\Delta P_{f t}^{e}-$ they will not price in expected inflation estimates.

Finally, we should further justify that out framework is a properly general theory. If this is indeed the case then it can generate the standard market equilibrium model of an upwardsloping supply curve and a downward-sloping demand curve as a special case. We can do this easily by providing a closure in which investment is set as a negative function of price and production/inventory offloading is a positive function of price. Or,

\section{$1.14 \chi_{f} \Delta P_{t}^{e}=f\left(P^{-}\right)$}

And,

\section{$1.15 q Z_{t}=f\left(P^{+}\right)$}

\subsection{General Theory of Pricing}

In the previous section we laid out a general theory of financial prices. We noted above, however, that goods in a capitalist economy fall into three categories: (i) pure assets; (ii) impure assets; and (iii) pure goods/services. The framework laid out in the previous section can only deal with pure assets and the financial component of impure assets. In order to derive a theory that can deal with both components of impure assets and pure goods we must introduce what we shall term a 'fundamental demand component'. Such a component denotes the amount of demand for a good that is not subject to financial consideration - so, for example, the component of demand for a vehicle that is the value derived from driving it without taking into consideration its appreciation/depreciation. 
The reason that we left out this 'fundamental' demand component from our theory of financial pricing is because once we concede that markets for assets rely solely on expectations there is no room for such fundamental demand. As we have seen, contemporary theories, like the EMH, avoid this by positing that there exists in the world some battery of information that is then interpreted perfectly by rational economic agents (Fama 1970) - this view is also upheld in noise trader models under the rubric of the 'rational' trader (Delong et al 1990). Such a view has already been called into question on empirical grounds (Shiller 2003) but is also suspect on ontological grounds ${ }^{13}$.

As stated, in many markets there does exist such a fundamental demand mixed with purely financial demand - as if the case in of housing but also with vehicles and any other asset with a resale value - these are the markets for what we have called 'impure assets'. In other markets, however, there exists only fundamental demand as the goods have no resale value at all - the markets for haircuts is a good example - and these we have termed 'pure consumer goods'.

In order to include a real demand component and be accounting consistent we must redefine our basic assumptions to allow that the purchases of some goods, like housing and vehicles, while they may have a speculative or financial component nevertheless add to real income. We can do this by adding a standard expenditure function that can be broken down into

\footnotetext{
${ }^{13}$ There is a strong implicit assumption in the EMH that the market is reflecting the optimal outcome at any given point in time. By assuming that market participants are rational and that prices merely reflect correct information this in turn assumes that financial markets are inherently stable. As Shiller says that "[contained in the EMH is] the idea that speculative asset prices such as stock prices always incorporate the best information about fundamental values and that prices change only because of good, sensible information." (Shiller 2003, p83).

We might put this same point more formally by saying that the term $\theta_{t}$-that is, the information term - in Fama's EMH model (Fama 1970) makes strong assumptions about both the psychology of market actors together with the quality of the information they possess. The former are thought to be so-called 'rational', emotionless information processors not unlike computers while the latter is thought to be a crystal clear perfectly transparent set of dictates or commands that are not open to any interpretation.

Needless to say, these are extremely dubious assumptions and appear to stem from a basic ontological confusion between the type of information humans process - which is context-dependent and open to interpretation - and the type of information that machines process - which is neither context dependent nor open to interpretation. This confusion, in turn, rests on a view of human beings that has long held sway in economics since the mid-twentieth century. It is essentially a view of human beings that derives its conception of man from the science of cybernetics - something that critics of equating cybernetic processes with human thought processes have long warned against on ontological grounds (Dreyfus 1992).

It is thus obvious that once we make the assumption that asset prices are dictated by expectations rather than information with a single interpretation processed by entities resembling robots or computers we cannot give any 'fundamental value' to what we delineated as the speculative component of the price of an asset in the last section.
} 
sectorial demand ${ }^{14}$. Thus for an asset, good or service which is not purely financial the following must hold,

$2.1 E_{f}+E_{r}=I_{f}+G_{f}+I_{r}+G_{r}+C_{r}$

Where those variables with a subscript $r$ are understood to be real variables as are those found entered in the national accounts. We can also view this from the income side, as we did in the previous section,

$2.2 Y_{f}+Y_{r}=S_{f}+T_{f}+S_{r}+T_{r}+C_{r}$

Since expenditure equals income we can substitute equation 2.1 into equation 2.2 to get,

$2.3 I_{f}+G_{f}+I_{r}+G_{r}+C_{r}=S_{f}+T_{f}+S_{r}+T_{r}+C_{r}$

We then move on to once again lay out the determinates of the price of assets that have both a real and a financial component from the demand side,

$2.4 Y_{f t}+Y_{r t}=E_{f t}+E_{r t}=\frac{P_{f t}+P_{r t}-p_{t-1}}{\delta}=I_{f t}+G_{f t}+I_{r t}+G_{r t}+C_{r t}$

So,

$2.5 I_{f t}+G_{f t}+I_{r t}+G_{r t}+C_{r t}=p_{t-1}+\chi_{r} \Delta P_{f t}^{e}+\chi_{f} \Delta P_{r t}^{e}+\Delta P_{r t}$

And,

$2.6 \frac{P_{f t}+P_{r t}-p_{t-1}}{\delta}=\chi_{f} \Delta P_{f t}^{e}+\chi_{r} \Delta P_{r t}^{e}+\Delta P_{r t}$

Or,

$2.7 P_{f t}+P_{r t}=p_{t-1}+\chi_{f} \delta \Delta P_{f t}^{e}+\chi_{r} \delta \Delta P_{r t}^{e}+\delta \Delta P_{r t}$

Once again, $\chi$ is to be understood in terms of equation 1.8. We can then aggregate the real and the financial components of the price movements,

${ }^{14}$ Once again, these equations can be applied either to all markets or to a single market. See footnote 12. 
$2.8 P_{f t}+P_{r t}=P_{t}$

So,

$2.9 P_{t}=p_{t-1}+\chi_{f} \delta \Delta P_{f t}^{e}+\chi_{r} \delta \Delta P_{r t}^{e}+\delta \Delta P_{r t}$

Then we complete our equation by adding a supply-side component as we did in our equations for purely financial assets and substitute our $\chi$ terms with a modified version of equation 1.7 which also includes a component that takes into account investors speculating on an increase in real demand and the profit they will potentially derive therefrom. Note that the supply-side component here has effects on both the financial and the real components of price.

$2.10 P_{t}=p_{t-1}+\left(\gamma_{f}-\pi_{f m}\right) \delta \Delta P_{f t}^{e}+\left(\gamma_{r}-\pi_{r m}\right) \delta \Delta P_{r t}^{e}-\delta q Z_{t}+\delta \Delta P_{r t}$

As with our oil example in the last section, a real world example might help in interpreting our new framework. As already stated at the beginning of this chapter, most markets for consumer durables in modern economies are fix-price markets. This means that producers must increase production or offload inventories, $q Z_{t}$, whenever there is a rise in demand for their product, $\Delta P_{r t}$, lest the price they have set break and begin to rise. But from our equation is should be clear that the speculative components of demand, $\Delta P_{f t}^{e}$ and $\Delta P_{r t}^{e}$, can also play a part in setting the final price and might require the additional offloading or production by the price-setter in order to counteract such pricing pressures.

The key lesson here is that speculators can indeed break fixed-price markets. This goes a long way to explaining why certain currency peg arrangements break down, for example. Sometimes such pegs break because of fundamentals - i.e. the country that has pegged the currency runs out of foreign currency reserves because it is running trade deficits or inadequate trade surpluses to back money creation - but sometimes such pegs break simply due to speculative activity on behalf of investors; again, the example of George Soros breaking the sterling peg to the European Exchange Rate Mechanism (ERM) in 1992 is instructive in this regard.

The above lesson is one of a potentially immeasurable series that can be derived from our general theory of prices. We bring them up only because currency markets - which blur the 
lines between being driven by fundamental forces, speculation and offloading of inventory - are particularly relevant for teasing out its implications and its robustness. But this theory, being a properly general theory, can be applied to the market for any asset; be it one that has no corporeal existence or resale value, like a haircut (by setting all expectational variables equal to zero), or one that has substantial resale value and a very real corporeal existence, like a house. The flexibility of the theory allows us to understand any and all types of markets simply by thinking through how they are structured and inserting the variables accordingly. The theory then provides what Keynes thought that all theory should provide. Not a pre-determined, teleological endpoint for where the world would be guaranteed to end up, but rather "an organised and orderly method of thinking out particular problems" (Keynes, 1936. Chapter 21).

\subsection{The Paradox of Speculative Profits}

Although we have already laid out above some potential applications of our framework, there is nevertheless one internal aspect to the theory that provides a fresh insight into the functioning of markets that include a speculative demand component - i.e. markets for both pure and impure assets. We will refer to this aspect of the theory as the 'paradox of speculative profits' and shall lay out its implications by examining it in detail using a highly simplified hypothetical example.

The paradox arises due to the existence of the barrier profit term that we introduced in equation 1.8. What this term implies is that investors take a certain degree of risk when speculating on the future value of an asset and in order to incur such risk they must receive a minimum amount of profit to do so. This minimum or barrier level of profit then holds in check any investment in the asset past this point. A simple example will prove illustrative in this regard.

Let us imagine a purely financial market with no capacity to increase the supply of the asset like that laid out in equation 1.9. Let us further imagine that this entire market is made up of three private investors; Investor A, Investor B and Investor C. Assume also that they have an identical amount of money that they are willing to invest - i.e. they are uniform in their ability to drive price - and that the price elasticity of demand, $\delta$, is 1 . Assume that the beginning price level of the asset, $p_{t-1}$, is 100 and that each investor holds an identical view of where the price

of the asset, $\Delta P_{f t}^{e}$, will rise to; allow this expected increase in price to be 40 . Now imagine that each investor has a different minimum or barrier profit, $\pi_{m}$, that they require to compensate for 
the risk undertaken in making the investment. We lay out these different barrier profits in Table 1.1 below.

Table 1.1

\begin{tabular}{|c|c|c|}
\hline & Minimum/Barrier Profit $-\pi_{m}$ & $\pi_{m}$ as a \% of $\Delta P_{f t}^{e}$ \\
\hline Investor A & 15 & $37.5 \%$ \\
\hline Investor B & 10 & $25 \%$ \\
\hline Investor C & 5 & $12.5 \%$ \\
\hline Average & 10 & $25 \%$ \\
\hline
\end{tabular}

As we can see from Table 1.1 the average barrier profit for the entire market is 10, or $25 \%$ of the total expected increase. Thus the market, as a whole, requires a $25 \%$ profit in order to take the risk of speculating on the investment. This means that the market will only drive the price the price up to $75 \%$ of the expected price rise because they will require a $25 \%$ level of compensation; or, to put this in numerical terms, despite the fact that they believe that the price will go up by 40, they will nevertheless only drive it up by 30 as a result of their holding back in order to make an expected minimum profit of 10.

This insight produces two interesting and relevant results. Firstly, it tells us that should investors require a reasonably substantial profit in order to speculate on an asset, the market for the asset will always undershoot the amount by which, in the aggregate and on average, the investors expect the market to rise by. This is a structural feature of such markets and goes a long way to explaining, for example, why investors regularly overestimate the expected gains (or losses) that a market might make.

Secondly, and tied to this, the paradox of speculative profits tells us that in any given speculative market the aggregate investors' profit margins will fall short of their expected barrier profit margins; and the reason for this is structurally tied to these very barrier profit expectations. Consider Table 1.2 below which shows how our three hypothetical investors' portfolios fared after they had invested in line with their expectations. 
Table 1.2

\begin{tabular}{|c|c|c|c|c|}
\hline & $\begin{array}{c}\text { Barrier Profit }- \\
\pi_{m}\end{array}$ & $\begin{array}{c}\pi_{m} \text { as a \% } \\
\text { of } \Delta P^{e}{ }_{f t}\end{array}$ & $\begin{array}{c}\text { Expected Profit at } \\
\text { Time } t\end{array}$ & $\begin{array}{c}\text { Actual Profit at } \\
\text { Time } t\end{array}$ \\
\hline Investor A & 15 & $37.5 \%$ & $40-15=25$ & $30-15=15$ \\
\hline Investor B & 10 & $25 \%$ & $40-10=30$ & $30-10=20$ \\
\hline Investor C & 5 & $12.5 \%$ & $40-5=35$ & $30-5=25$ \\
\hline Average & 10 & $25 \%$ & 30 & 20 \\
\hline
\end{tabular}

As we can see, the average expected profit in the market was 30 or $75 \%$ of the expected rise in the price of the asset. Because the rise in the price of the asset was, however, only 30 rather than the expected rise of 40, the average actual profit in the market was only 20 or $50 \%$ of the initial expected rise. These dynamics, which can be explored in far more complex detail for example, by varying investors' expectations of price changes, $\Delta P_{f t}^{e}$, and the price elasticity of demand, $\delta$-are the result of what we call the paradox of speculative profits.

This insight can be integrated, for example, into a broadly Minskyan framework in order to explain why speculators do not see their expected returns and thus see their equity-to-debt ratios rise. Indeed, it strongly reinforces Hyman Minsky's theories regarding the fragile nature of capitalist financial systems as it shows how they can endogenously create shortfalls in expected returns due simply to the fact that they operate based on a profit motive.

\subsection{A Consideration of Kaleckian Price Dynamics}

As we laid out earlier, Kalecki postulated that we should understand that primary and secondary goods markets have entirely different price dynamics. Because the situation in primary goods markets was typically one of full employment of resources and thus scarcity Kalecki reasoned that, not only should we expect substantial price volatility, but we should also expect speculation to play an enormous role. This was not, however, true of secondary goods markets because they were characterised by fixed prices and flexible supply. 
Having laid out our theoretical framework we can now discuss Kalecki's insights in more detail. What Kalecki recognised was not simply true for secondary goods markets, it was true for the market for any good that (a) is a pure or impure asset and (b) does not, for whatever reason, have any capacity to increase supply. As we discussed above, such is the case, for example, in the market for a pegged currency; once the ability of the holder of inventory (the central bank) can no longer alter supply (in this case, restrict the supply of the domestic currency by making purchases in the foreign exchange markets using their foreign exchange inventories) the market becomes subject to speculative forces.

This leads to somewhat startling conclusion that those markets that approximate those typically imagined in marginalist theories - i.e. those where price rather than quantity adjusts are in fact the very markets which produce instability. While it is those markets that approximate the ones imagined in Post-Keynesian fixed-price theory that ensure stability. In a sentence: free markets lead, not to stability, but rather to instability while fixed-price markets lead to stability.

\subsection{Beyond Price Stickiness}

As is well known, New Keynesian and Neo-Keynesian macroeconomic theories typically rely on the idea of 'sticky' wages and prices to produce below full employment equilibrium results, i.e. to overturn Say's Law. If we substitute the above theory of pricing for the standard marginalist theory of pricing, however, we need no longer assume that prices are sticky in order for the market to clear.

The reason for this is due to the distinction we laid out above between speculative and fundamental demand. As we showed above, investment may flow into either channel. It thus need not be assumed in our framework that investment capital flows into sectors that will increase both output and income. Rather it might flow into sectors that lead only to increases in prices through the process of speculation and only to a rise in financial income which, of course, is not counted in the standard measures of income.

The end result is that investment capital may simply drive up prices through the process of speculative demand and not increase real incomes or output. This increase in prices will then, ceteris paribus, ensure that markets do not clear and no full employment equilibrium is reached. By doing away with the notion of market equilibrium in the setting of prices we have, in a sense, completed the Keynesian revolution in that we cannot assume whatsoever that markets 
will clear given flexible wages and prices $^{15}$ - indeed, as we have seen in our discussion of Kaleckian price dynamics the latter may actually encourage speculation, exacerbate price increases and thus ensure that markets do not clear.

\section{CONCLUSION}

At the beginning of this paper we argued that financialisation has been recognised as being increasingly important since the financial crisis of 2008. At the same time many of the theories and frameworks used to approach the financial sector with respect to pricing and speculation have been called increasingly into question. The objective of this paper was to remedy this to some extent.

In the first section we engaged in a survey of the relevant literature on the functioning of financial markets in general and the phenomenon of speculation in particular. In doing so we found an interesting plurality of theories that, while they differed in both structure and intention, nevertheless shared common characteristics with one another. Where some were strong in one area, they were weak in others.

The primary weakness that we found with these models was that they required an assumption of market equilibrium. Only the Behaviourist approach and a few authors like Davidson (1996) and Soros (2003) were able to avoid this, and they did so only by means of not laying out any formal analytical framework. At the same time, some of the components of the analytical frameworks that we surveyed were of great interest and relevance if they could be torn from their reliance on market equilibrium. Indeed, Beja and Goldman (1980) were shown to have articulated a model that eschewed market equilibrium outcomes; but they did so only in the context of respecting the broader idea that generally markets tended toward market equilibrium. This prevented them from being able to extend and generalise their framework.

In the second section we showed that there is a different framework that can be used to approach the pricing of assets or goods with a financialised component. We noted that this framework had come about as the result of the Keynesian revolution in macroeconomics and

\footnotetext{
${ }^{15}$ Note that we do not make a claim to originality here. Kaldor (1939) recognised well that if speculative demand could lead to price increases then there was no need to assume wage and price stickiness for a below full employment equilibrium to be reached in the goods market. Indeed, after Kaldor's paper was republished in 1960 John Hicks said that it was "the culmination of the Keynesian revolution in theory. You [Kaldor] ought to have had more credit for it." (King 2007, p50). This further buttresses our argument laid out above of the importance of a properly Keynesian conception of prices for a full and coherent articulation of Keynesian theory.
} 
was explicitly seen by many advocates (Kaldor 1985 and Godley 1997) as being an alternative to market equilibrium theories.

In the third section we used such a framework to build a general theory of asset pricing that could deal with the three classes of purchases we identified at the beginning of that chapter (which encompass all possible purchases). This theory incorporated and extended the familiar macroeconomic identities that are built into the national accounting framework and thus also provides a potential means to discuss financial transactions in such a framework while they also allow us to engage in a sectorial breakdown of demand for such assets.

While we were somewhat reticent to 'close' the model in light of Keynes' methodological criticisms we nevertheless provided a suggested closure for a specific market (the stock market) in which we showed how closures could be incorporated after taking into account the empirical structure of any given market. We also provided a closure that would turn our general theory of pricing back into the special case of a downward-sloping demand curve and an upward-sloping supply curve that we examined at length in the second chapter.

Next we examined some of the most interesting, non-applied components of our framework. The first of these was the 'paradox of speculative profits'. This paradox goes a long way to explaining certain important characteristics of real world financial markets; most notably, the fact that in them expectations often tend to rush ahead of the actual price rises that result. So far as we know, this is a completely novel observation and has never been made in the literature before. It should also be of interest to financial market participants as it provides an interesting insight into the function of the markets; its dynamics can also be explored in great detail if the other terms in our equations are given different numerical values. We also suggested that the paradox of speculative profits can be used by those studying Hyman Minsky's theories of financial instability to better understand how and why economic agents might engage in speculative bets that do not pay off their expected return.

We also explored in more detail the nature of Kalecki's insights on price dynamics and found that they could be generalised to many markets using our framework. By doing so we could overturn the idea inherent in mainstream economics that flexible price markets lead to stability; rather we reached quite the opposite conclusion. Finally, we noted that our theory of prices leads to a new justification for the Keynesian approach to macroeconomics that does not rely on 'sticky' wages and prices. By disaggregating investment flows into their speculative and 
fundamental components we saw how speculative investment could drive prices up which would, in turn, lead markets not to clear. 


\section{REFERENCES}

Baker, Dean. (2009). Plunder and Blunder: The Rise and Fall of the Bubble Economy. USA: PoliPointPress.

Beja, Avraham \& Goldman, M. Barry. (1980). 'On the Dynamic Behavior of Prices in Disequilibrium'. The Journal of Finance. 35(2). Pp235-248.

Bernanke, Ben. (2004). 'Oil and the Economy'. Distinguished Lecture Series, Darton College, Albany, Georgia. Available at:

http://www.federalreserve.gov/boarddocs/speeches/2004/20041021/

Bernanke, Ben \& Gertler, Mark. (2001). 'Should Central Banks Respond to Movements in Asset Prices?'. American Economic Review. 91(2). Pp253-257.

Black, Fischer. (1986). 'Noise'. Journal of Finance. 41(3). Pp529-543.

Blinder, Alan; Canetti, Elie \& Lebow, David. (1998). Asking About Prices: A New Approach to Understanding Price Stickiness. Russell Sage Foundation.

Cipriani, Marco \& Guarino, Antonio. (2005). 'Herd Behaviour in a Laboratory Financial Market'. American Economic Review. 95(5). Pp1427-1443.

Davidson, Paul. (1996). 'Reality and Economic Theory'. Journal of Post Keynesian Economics. 18(4). Pp479-508.

Davidson, Paul. (2008). 'Crude Oil Prices: 'Market Fundamentals' or Speculation?'. Challenge. 51(4). Pp110-118.

Delong, Brad; Scleifer, Andrei; Summers, Lawrence \& Waldmann, Robert. (1990). 'Noise Trader Risk in Financial Markets'. Journal of Political Economy. Pp703-738.

Dreyfus, Hubert. (1992). What Computers Still Can't Do: A Critique of Artificial Reason. USA: MIT Press.

Eiteman, Wilford \& Guthrie, Glenn. (1953) 'The Shape of the Average Cost Curve'. The American Economic Review. 43(4). Pp. 628-630.

Fama, Eugene. (1970). 'Efficient Capital Markets: A Review of Theory and Empirical Work'. The Journal of Finance. 25(2). Pp383-417.

Fattouh, Bassam. (2011). 'Uncertainty, Expectations and Fundamentals: Whatever Happened to Long-Term Oil Prices?’. The Oxford Institute for Energy Studies. Available at: http://www.oxfordenergy.org/wpcms/wp-content/uploads/2011/03/Comment-March2011_1.pdf

Fattouh, Bassam. Kilian, Lutz \& Mahadava, Lavan. (2012). 'The Role of Speculation in the Oil Market: What Have We Learned So Far?'. CEPR Discussion Paper Series. Available at: http://www-personal.umich.edu/ 1kilian/milan030612.pdf

Galbraith, John Kenneth. (1954). The Great Crash 1929. UK: Pelican Books. 
Galbraith, John Kenneth. (1990). A Short History of Financial Euphoria. USA: Pelican Books.

Godley, Wynne. (1997). 'Macroeconomics Without Equilibrium or Disequilibrium'. Working Paper No. 205. The Levy Institute of Bard College. Available at: http://128.118.178.162/eps/mac/papers/9801/9801002.pdf

Godley, Wynne and Lavoie, Marc. (2012). Monetary Economics: An Integrated Approach to Credit, Money, Income and Wealth. USA: Palgrave Macmillan.

Grossman, S. \& Stiglitz, J. (1980). 'On the Impossibility of Informationally Efficient Markets'. The American Economic Review. 70(3). Pp393-408.

Harrison, Anne. (2006). 'Definition of Economic Assets'. Fourth Meeting of the Advisory Expert Group on National Accounts. Available at: https://unstats.un.org/unsd/nationalaccount/aeg/papers/m4EconAssets.PDF

Jolink, Albert \& Van Daal, Jan. (1993). The Equilibrium Economic of Leon Walras. USA: Routledge.

Juvenal, Luciana \& Petralla, Ivan. (2012). 'Speculation in the Oil Market'. Research Division: Federal Reserve Bank of St. Louis. Working Papers Series. Available at: http://research.stlouisfed.org/wp/2011/2011-027.pdf

Kaldor, Nicholas. (1939). 'Speculation and Economic Stability'. The Review of Economic Studies. 7(1). Ppl-27.

Kaldor, Nicholas. (1985). Economics Without Equilibrium. USA: M.E. Sharpe.

Kalecki, Michal. (1965). Theory of Economic Dynamics: An Essay on Cyclical and Long-Run Changes in Capitalist Economies. USA: Monthly Review Press.

Keynes, John Maynard. (1936). The General Theory of Employment, Money and Interest. Available at: http://www.marxists.org/reference/subject/economics/keynes/generaltheory/

Kindleberger, Charles. (2005). Manias, Crashes and Panics: Fifth Edition. USA: John Riley and Sons.

King, John. (2007). 'Not the Devil's Decade: Nicholas Kaldor in the 1930s'. History of Economics Review. No. 46. Pp39-61. Available at: http://ssrn.com/abstract=1077017

Kirkpatrick, Charles \& Dahlquist, Julie. (2006). Technical Analysis: The Complete Resource for Financial Market Technicians. Financial Times/Prentice Hall.

Lakatos, Imre. (1978). The Methodology of Scientific Research Programs: Philosophical Papers Volume I. USA: Cambridge University Press.

Lavoie, Marc. (1992). Foundations of Post-Keynesian Economic Analysis. UK: Edward Elgar.

Malkiel, B. (2003). 'The Efficient Market Hypothesis and Its Critics'. Journal of Economic Perspectives. 17(1). Pp59-82. 
Marshall, Alfred. (1890). Principles of Economics: Eighth Edition. USA: Cosimo Classics.

Masters, Michael. (2008). 'Testimony of Michael W. Masters Before the Committee on Homeland Security and Governmental Affairs, United States Senate'. Available at: http://www.hsgac.senate.gov//imo/media/doc/052008Masters.pdf?attempt=2

Robinson, Joan. (1956). The Accumulation of Capital. UK: Macmillan and Co. Ltd.

Rothbard, Murray. (2000). America's Great Depression: Fifth Edition. USA: Mises Institute. Available at: http://mises.org/rothbard/agd.pdf

Samuelson, Paul \& Nordhaus, William. (1995). Economics: Fifteenth Edition. USA: McGrawHill.

Singleton, Kenneth J. 2012. 'Investor Flows and the 2008 Boom/Bust in Oil Prices'. Working paper. Stanford University. Available at: http://ssrn.com/abstract=1793449

Senate Staff Report. The Role of Market Speculation in Rising Oil and Gas Prices: A Need to Put the Cop Back on the Beat. $109^{\text {th }}$ Congress, $2^{\text {nd }}$ Session. USA: US Government Printing Office. Available at: http://www.gpo.gov/fdsys/pkg/CPRT109SPRT28640/pdf/CPRT-109SPRT28640.pdf

Shiller, Robert. (2003). 'From Efficient Markets Theory to Behavioral Finance'. Journal of Economic Perspectives. 17(1). Pp83-104.

Shiller, Robert. (2005). Irrational Exuberance: Second Edition. USA: Broadway Business Books.

Soros, George. (2003). The Alchemy of Finance: Reading the Mind of the Market. USA: Wiley.

Wessen, Joseph Paul. (1998). 'The Teleological Impulse: Thorstein Veblen, Existentialism and the Philosophy of Science'. Method and History of Economic Thought. No. 9808002. Available at: http://ideas.repec.org/p/wpa/wuwpmh/9808002.html

Wray, Randall. (1998). Understanding Modern Money: The Key to Full Employment and Price Stability. UK: Edward Elgar.

Wray, Randall. (2008). 'The Commodities Market Bubble: Money Manager Capitalism and the Financialization of Commodities'. Levy Institute Public Policy Brief No. 96. Available at: http://www.levyinstitute.org/pubs/ppb_96.pdf

Varian, Hal. (2010). Intermediate Microeconomics: A Modern Approach: Eighth Edition. USA: W.W. Norton and Company. Available at: http://unctad.org/en/PublicationsLibrary/wir2013_en.pdf (Accessed: 3 July 2013). 